\title{
Nuevos documentos para la biografía de Miguel de Cervantes Saavedra, un comisario real de abastos en los antiguos Reinos de Jaén y Sevilla $(1592-1593)$
}

\author{
José CABello NúÑEZ*
}

\begin{abstract}
Resumen
El reciente hallazgo de nuevos testimonios escritos sobre Miguel de Cervantes conservados en varios archivos sevillanos, ha permitido atestiguar su presencia en Sevilla y en varios lugares de su comarca ejerciendo el oficio de comisario real de abastos en la primavera del año 1593. Estos testimonios esclarecen un periodo hasta ahora oscuro en su biografía, y al mismo tempo acrecientan nuestros conocimientos sobre sus actividades en la villa de Porcuna (Jaén), donde ejerció su labor de comisario en enero de 1592. La nueva documentación no sólo ofrece información sobre una desconocida comisión, encomendada a Cervantes el 21 de febrero de 1593 por Cristóbal de Barros, el proveedor general de la Flota de la Carrera de las Indias, sino que proporciona además el nombre de una mujer sevillana, doña Magdalena Enríquez, comerciante dedicada a la fabricación de bizcocho para la Armada, a la que Cervantes facultó ante escribano público para que pudiera cobrar el salario que se le adeudaba por este servicio. Es destacable la estrecha amistad de Cervantes con Magdalena Enríquez así como también con Tomás Gutiérrez. En total, son catorce los nuevos documentos cervantinos que, por vez primera, se reúnen y transcriben en esta publicación. Aunque seis de ellos ya fueron editados entre 2014 y 2015, los ocho restantes son inéditos. Con estas aportaciones documentales se abren, pues, nuevas vías de investigación para profundizar en la enigmática vida del autor del Quijote.
\end{abstract}


Palabras clave: Miguel de Cervantes Saavedra; Magdalena Enríquez; Cristóbal de Barros; Sevilla; Jaén; Comisario real de Abastos.

Title: New documents for the biography of Miguel de Cervantes Saavedra, a royal commissar of supplies in the former Kingdoms of Jaen and Seville (1592-1593)

\begin{abstract}
The recent finding of new testimonies on Miguel de Cervantes life, preserved in several Sevillian archives, has helped to clarify his presence in Seville and other places of this region exercising as Royal Commissioner of Supplies in spring of 1593. These testimonies clarify a dark period in his biography, and increase our knowledge of his activities in Porcuna (Jaén) as Royal Commissar of Supplies in January 1592. The new documentation offers information about an unknown commission entrusted on February 211593 to Cervantes by Cristobal de Barros, the general supplier of the Carrera de las Indias' fleet. These papers also provide the name of a Sevillian woman, Magdalena Enriquez, a merchant who manufacture "biscochos" for the Navy, who legally was authorized by Cervantes to collect the salary owed for his services in that institution. It is remarkable the narrow relation of friendship between Cervantes and this woman, and also with Tomas Gutiérrez. In sum, this article provides fourteen new Cervantian documents that I meet and transcribe for Anales Cervantinos. Six of these documents were already edited between 2014 and 2015, and the other eight are published for the first time. With this documentary contribution new research routes are open to penetrate into the enigmatic life of the author of Don Quixote.
\end{abstract}

Key words: Miguel de Cervantes Saavedra; Magdalena Enriquez; Cristobal de Barros; Seville; Jaen; Royal Commissar of Supplies.

Cuando nos encontrábamos a las puertas de celebrar el IV centenario de la publicación de la segunda parte de El Ingenioso Caballero don Quijote de la Mancha (1615-2015) y aún teníamos en ciernes la conmemoración de otra efemérides no menos importante, la del IV centenario de la muerte de su autor, Miguel de Cervantes Saavedra (1616-2016), nuestro escritor más insigne y universal, se hicieron públicos con notoria presencia en diversos medios de comunicación, tanto nacionales como internacionales, los resultados de mis investigaciones sobre la presencia de Cervantes en Andalucía durante su etapa de comisario real de abastos, ofreciéndonos datos de excepcional interés para poder profundizar en el conocimiento de su agitada y aún enigmática vida, ${ }^{1} \mathrm{a}$

1. Agencia EFE (26 de marzo de 2014), "Cervantes, el recaudador de impuestos", en Diario de Sevilla, disponible en la dirección Web: http:/www.diariodesevilla.es/article/sevilla/1738087/miguel/ cervantes/recaudador/impuestos.html. Valenzuela, Alfredo (12 de agosto de 2014), "Hallan en Sevilla documentos inéditos vinculados a Cervantes", en Diario de Sevilla, p. 45. Linares, Rocío (12 de agosto de 2014), "La dama oculta de Cervantes, en La Razón, edición de Sevilla, p. 4. Diaz Pérez, Eva (12 de agosto de 2014), "Misterio sobre Cervantes en un legajo sevillano", en El Mundo, edición de Sevilla, p. 6. Valenzuela, Alfredo (4 de enero de 2015), "Cervantes, el recaudador", en El Correo de Andalucía, p. 24. Valenzuela, Alfredo (19 de diciembre de 2015), "Otra mujer en la vida de Cervantes", en El Mundo, disponible en la dirección Web: http://www.elmundo.es/andalucia/2015/12/19/ $567554 \mathrm{~b} 9268 \mathrm{e} 3 \mathrm{e} 14138 \mathrm{~b} 4616 . \mathrm{html}$. 
los que más tarde se sumaron los obtenidos por otros archiveros municipales e historiadores locales sevillanos ${ }^{2}$.

Serían precisamente seis testimonios documentales relacionados con $\mathrm{Mi}$ guel de Cervantes, entonces nuevos e inéditos, descubiertos por mí en el Archivo General de Indias y en los archivos de protocolos notariales de La Puebla de Cazalla y Sevilla, todos dados a conocer y publicados entre los años 2014 y $2015,{ }^{3}$ los que acapararon la atención preferente de la prensa especializada, de los archiveros, cervantistas y asociaciones cervantinas repartidas por todo el mundo, pues aportan datos relevantes que permiten aclarar algunos de los múltiples enigmas que aún existen sobre la vida y la obra de Cervantes, singularmente los referidos a sus actividades profesionales y relaciones personales mientras recorría los caminos de Andalucía en el desempeño de su trabajo como criado del Rey; testimonios que hasta entonces habían permanecido ocultos entre los seculares legajos de los citados archivos sevillanos y que ahora, una vez sacados a la luz, han permitido acreditar sin ningún género de dudas la presencia cierta de Cervantes en la ciudad de Sevilla y en varios municipios de su comarca en un periodo cronológico de su vida (cuarenta y ocho días entre febrero y abril del año 1593) desconocido y rodeado hasta ahora de grandes incógnitas.

La conmemoración del IV Centenario de la muerte de Miguel de Cervantes es una ocasión propicia para poner en práctica las recomendaciones que en su día ofreciera Krzystof Sliwa: «(...) Por favor, que se publiquen los documentos cervantinos en las revistas cervantinas, donde estarán accesibles a todos. Me parece deseable incluso sugerir a los archiveros españoles, de parte de la Asociación de Cervantistas, que si alguien descubre un documento cervantino que lo publique en una de estas revistas» ${ }^{4}$. En nuestro caso, el momento elegido no ha podido ser más a propósito.

Así, acatando los deseos de Sliwa, hemos querido aprovechar la esplendida oportunidad que se nos brinda para poder reunir aquí, por vez primera, no sólo las transcripciones de los seis nuevos documentos cervantinos de $1593^{5}$, cuando nuestro escritor aún se encontraba en el antiguo Reino de Sevilla ejerciendo las labores de comisario real de abastos, sino dando también a conocer otros ocho documentos asimismo inéditos, hallados recientemente por mí en el Archivo Histórico Provincial de Sevilla, relativos a los servicios prestados por Cervantes a la Corona en tierras de Sevilla (año 1593) y Jaén

2. Martin Ojeda, (2015: 149-187). Mayo Rodriguez (2015: 1-7), disponible en la dirección web: http://www.moderna.ih.csic.es/fmi/xsl/fehm/anexos/ArtíiuloCervantes-VíaMarciala-feb2015.pdf.

3. Cabello Núñez (2014: 57-71). Cabello Núñez (2015: 75-147).

4. Sliwa (1997: 178), disponible en la dirección web:

http://cvc.cervantes.es/literatura/cervantistas/coloquios/cl_VII/cl_VII_13.pdf.

5. Dos de ellos son asientos contables en la data de las cuentas presentadas en 1596 por Francisco de Agüero, pagador de la Real Armada, donde se justifican los gastos y pagos realizados entre los años 1593 y 1596 para el aprovisionamiento de los galeones que escoltaban a las Flotas de la Carrera de las Indias, entre las cuales se incluyen las correspondientes a la comisión que el proveedor general Cristóbal de Barros encomendó a Cervantes el 21 de febrero de 1593. 
(año 1592), poniéndolos a disposición de todos cuantos nos aventuramos a investigar sobre la vida y la obra del Príncipe de las Letras ${ }^{6}$.

Por tanto, ofrecemos y comentamos en las páginas siguientes las transcripciones de un total de catorce documentos nuevos sobre Miguel de Cervantes, los cuales eran desconocidos: seis que ya fueron publicados anteriormente, y otros ocho totalmente inéditos que aquí ven la luz por primera vez, aumentando así el corpus documental cervantino hasta ahora conocido. En este punto, y con ánimo de ser más precisos y rigurosos, creo conveniente aclarar que tres de esos ocho testimonios nuevos ${ }^{7}$ podrían ser considerados como referencias a documentos cervantinos de cuya existencia se deja debida constancia en los textos notariales que aquí se transcriben, y aunque no dispongamos de esos tres documentos en su integridad por no haberse podido hallar aún en los archivos (si es que todavía se conservan), no es menos cierto que los documentos que aparecen citados en dichos protocolos notariales llegaron a otorgarse realmente y tuvieron plena validez jurídica y contable. De modo que, aunque actualmente desconozcamos el paradero de tres de ellos, la mera constancia de su verdadera expedición y datación han de servirnos como guía para, al menos, intentar su búsqueda y localización en otra etapa de nuestras investigaciones, pudiendo encontrarse los originales, o un traslado de los mismos, entre los legajos de cualquier otro archivo, pues como bien señaló Astrana Marín al referirse a la búsqueda de documentos cervantinos, que estos «(...) han surgido a veces cuando menos se esperaba, porque los documentos se presentan a menudo cuando ellos quieren, y no siempre que se los busca. Sin el auxilio de la Fortuna, un investigador puede perder las narices husmeando papeles y no encontrar ninguno de los que va persiguiendo» ${ }^{8}$.

De Miguel de Cervantes sabemos, con certeza, que entre los años 1587 y 1594 anduvo por los caminos de los antiguos Reinos de Sevilla, Córdoba, Granada y Jaén, ejerciendo las ingratas labores de comisario real de abastos y recaudador de impuestos atrasados a la Corona; tareas que le provocaron importantes quebraderos de cabeza durante las conflictivas negociaciones que hubo de mantener con los Ayuntamientos y vecinos de las ciudades, villas y lugares que se vieron afectados por las requisas de trigo, cebada, aceite y otros víveres necesarios para el abastecimiento de las galeras y galeones de la Armada Imperial y de las Flotas de la Carrera de las Indias, llegando incluso a ser excomulgado temporalmente por el Arzobispado de Sevilla cuando se enfrentó a algunos representantes del estamento eclesiástico, quienes lo acu-

6. Valenzuela, Alfredo (26 de junio de 2016), "Hallan siete nuevos documentos sobre Cervantes y su etapa andaluza", en Diario de Sevilla, p. 52. "Cervantes al descubierto", en El Correo de Andalucía, p. 56.

7. Una certificación de Miguel de Cervantes, fechada el 13 de enero de 1592; un poder notarial, otorgado el 18 de mayo de 1592, y una libranza de 7 de septiembre de 1592.

8. Astrana Marin, (1948-1958: I, CXXV), disponible en la dirección web:

http://www.publiconsulting.com/pages/astrana/tomoI/p0000003.index.htm. 
saron de haberles sacado indebidamente ciertas cantidades de trigo que tenían almacenadas en sus fábricas 9 .

Sobre las actividades y lugares de residencia de Cervantes entre los años 1595 y 1600 aún existen muchas dudas y un importante vacío documental, aunque es sobradamente conocido su ingreso en la Cárcel Real de Sevilla, donde estuvo preso entre septiembre de 1597 y los primeros meses del año 1598. En ella entró acusado de haber defraudado a la Corona, pues los contadores y tesoreros de la Contaduría Mayor de Hacienda detectaron algunos descuadres no muy bien justificados por Cervantes en las cuentas que había presentado al finalizar las comisiones. Su rastro se diluye y prácticamente se pierde en Andalucía a partir del mes de febrero de $1599^{10}$, considerándose que fueron continuos sus viajes entre Sevilla, Esquivias, Toledo y Madrid para atender asuntos familiares y negocios particulares. Aunque es muy probable que su residencia en tierras andaluzas hubiera podido prolongarse más allá del 2 de mayo 1600, última fecha en la cual consta documentada su actividad en la ciudad de la Giralda ${ }^{11}$, nada cierto sabremos de él hasta el 27 de enero de 1602, cuando se encuentra en Esquivias actuando como padrino del bautizo de una hija de Bartolomé de Ugena. No constan más noticias fidedignas sobre su paradero hasta el 11 de abril de 1605, cuando documentalmente se acredita su presencia en Valladolid, ciudad a la que se había trasladado la Corte de Felipe III y en la que nuestro escritor otorgará poder al librero Francisco de Robles para imprimir, distribuir y vender la primera parte de su Quijote en los Reinos de Portugal, Aragón, Valencia y Cataluña ${ }^{12}$.

Aunque la intensa actividad desarrollada por Miguel de Cervantes durante su etapa de comisario real de abastos y recaudador de impuestos en Andalucía tuvo que generar una importante cantidad de documentación administrativa y contable, así como una correspondencia abundante e intensa con y entre los diferentes agentes que integraban la compleja maquinaria burocrática creada por Felipe II para el buen gobierno y exhaustivo control de su Imperio, desgraciadamente aún son muy escasas las pruebas documentales relacionadas con el desempeño de su oficio como criado del Rey que han llegado hasta nuestros días. La gran mayoría de los documentos donde aparece el nombre de Cervantes son, como hemos indicado, de carácter contable, notarial o judicial ${ }^{13}$, predominando aquellos que fueron generados o recibidos por éste durante su trabajo de comisario real de abastos en algunos lugares del antiguo Reino de

9. León Mainez (1901: II, 259-260).

10. Cervantes reside en Sevilla, en la collación de San Isidro. En ella, el 10 de febrero de 1599, otorgará carta de pago a favor de su sobrino Juan de Cervantes, justificativa de la devolución de un préstamo de 90 ducados. Cotarelo y Mori (1905: 176).

11. Cotarelo y Mori (1905: 183-184). Cervantes aparece en Sevilla como testigo en una petición realizada por su amigo Agustín de Cetina, pagador de la Real Armada, para que se le incluyera en el padrón de vecinos de la collación de San Nicolás.

12. Cotarelo y Mori (1905: 196-198).

13. Larroque Allende (1999: 253-262). 
Sevilla entre los años 1587 y 1593. Especialmente numerosos son los relacionados con su trabajo en la ciudad de Écija, donde pasó largas temporadas entre 1587 y 1589 acopiando aceite y recogiendo trigo para su molienda en las aceñas del río Genil, tareas que le obligaron a fijar su residencia en ella durante tres meses y medio ${ }^{14}$.

Muchísimo menor es, en cambio, el número de testimonios que acreditan su presencia como servidor de la Corona en algunas ciudades, villas y lugares de Córdoba, Granada, Málaga y Jaén, por donde también anduvo Cervantes los años 1591, 1592 y 1594, y de los cuales hizo referencia Luis Astrana Marín $^{15}$. No obstante, posteriores investigaciones facilitaron nuevos datos y documentos que acreditaban la presencia de Cervantes en Jaén y su comarca, destacando las de Juan Antonio Cabezas, Luis Coronas Tejada, Manuel Alcalá Sánchez y Pedro Javier Rivas ${ }^{16}$, que acrecentaron la escueta relación documental que sobre Jaén y su comarca había recopilado Astrana Marín. Por otra parte, las cartas, oficios, memoriales, informes y correspondencia diversa de carácter oficial que Cervantes, sin ningún género de duda, tuvo que mantener prácticamente casi a diario con los proveedores generales, los corregidores, alcaldes y regidores de los Ayuntamientos, escribanos y escribanos públicos, comisarios, tenedores de bastimentos, contadores, pagadores reales, jueces, alguaciles, oficiales y demás funcionarios implicados en el cumplimiento de sus comisiones para el aprovisionamiento de la Armada, son práctica y lamentablemente inexistentes.

También hemos querido contribuir a un mejor conocimiento de las actividades desarrolladas por el comisario Miguel de Cervantes en tierras de Sevilla y Jaén, aportando, en nuestro caso, un total de catorce documentos relativos a las sacas de trigo y cebada efectuadas por Cervantes los años 1592 y 1593 en diversas localidades andaluzas; pruebas documentales localizadas en el transcurso de mis investigaciones en el Archivo General de Indias y en los archivos de protocolos notariales de La Puebla de Cazalla y Sevilla. De esos catorce documentos cervantinos nuevos, ocho han permanecido inéditos hasta ahora; los seis restantes ya fueron publicados con anterioridad ${ }^{17}$.

Los nuevos documentos se relacionan y transcriben siguiendo la secuencia cronológica de su hallazgo en los expresados archivos sevillanos. Los seis primeros, descubiertos y publicados entre los años 2014 y 2015, se refieren a la nueva comisión dada a Cervantes el 21 de febrero de 1593 por el proveedor

14. Martin Ojeda (2015: 176). El día 1 de abril de 1589, Miguel de Cervantes pagó a Francisco Bermudo Bersabé, vecino de Écija y apoderado del doctor Francisco de Villacreces, la cantidad de 150 reales por el alquiler de unas casas donde estuvieron alojados él y sus ayudantes.

15. Astrana Marin (1948-1958), tomos IV y V.

16. Cabezas Candeli (1967: 298-299). Coronas Tejada (1979: 9-52). Alcalá Sánchez, (1990: 4346). Pérez Fernández (2013: 68-85), disponible en la dirección Web: https://drive.google.com/file/ d/0B_44jst5tZIcQmFId1ExLXphMmM/edit. Donaire, Ginés (27 de junio de 2001), "El recaudador de impuestos Cervantes", en El País, disponible en la dirección Web: http://elpais.com/diario/2001/06/27/ andalucia/993594155_850215.html.

17. Cabello Núñez (2014: 57-71). Cabello Núñez (2015: 75-147). 
general Cristóbal de Barros; un séptimo testimonio, hasta ahora inédito, datado en Sevilla el 28 de marzo de 1594, está relacionado con dicha comisión, y los siete restantes, igualmente inéditos, corresponden al año 1592, cuando Cervantes prestaba sus servicios como comisario real de abastos en la villa de Porcuna (Jaén), bajo las órdenes directas de Pedro de Isunza, el proveedor general de las galeras de España. Sus transcripciones se han reunido aquí por vez primera para facilitar su divulgación y el acceso de los investigadores y biógrafos de Cervantes.

Todos ellos han de ser considerados como documentos estrictamente cervantinos $^{18}$, no sólo por contener el nombre de Miguel de Cervantes, sino por tratarse además de testimonios originales y auténticos, de carácter administrativo, jurídico y contable, contemporáneos de Cervantes ${ }^{19}$, destacando sobremanera el nuevo poder notarial otorgado en Sevilla el 8 de julio de 1593, pues este lleva su firma autógrafa, una más que añadir a la colección de las ya conocidas y conservadas. Asimismo, tienen en común que fueron redactados cuando Cervantes se ganaba el sustento diario como comisario real de abastos, a las órdenes directas de los proveedores generales de las galeras de la Armada Imperial y de los galeones de las armadas que daban escolta a las Flotas de la Carrera de las Indias, con la misión de acopiar grandes partidas de trigo y aceite, cebada, garbanzos, habas, queso y otros bastimentos necesarios para la alimentación del personal embarcado en tales navíos, añadiéndose a su biografía los nombres de dos nuevos personajes con los que Cervantes tuvo relación: Cristóbal de Barros y Peralta, el primer proveedor general de los galeones de las Flotas de las Indias, y doña Magdalena Enríquez, una bizcochera sevillana con la que Cervantes pudo tener una especial vinculación profesional y de estrecha amistad.

\section{MIGUEL DE CERVANTES, COMISARIO REAL DE ABASTOS EN EL ANTIGUO REINO DE SEVILLA. DOCUMENTOS I AL VII}

Los siete documentos que transcribimos a continuación están directamente relacionados con la comisión que el comisario real de abastos, Miguel de Cervantes Saavedra, recibió el 21 de febrero de 1593 de manos del proveedor general Cristóbal de Barros, para sacar trigo, cebada y otras provisiones de algunos lugares de la comarca de Sevilla con las que abastecer a los navíos de guerra que escoltaban a las Flotas de la Carrera de las Indias.

Estas nuevas piezas documentales, expedidas mientras Cervantes residía en la ciudad hispalense y se desplazaba por algunos pueblos de la comarca de

18. Sliwa (1997: 175). El profesor Sliwa considera que "(...) un documento cervantino es un escrito en forma de una carta, relación, testimonio, cédula, asiento, pliego, informe, memorial, protocolo $\mathrm{u}$ otro que contiene una referencia al Manco de Lepanto o a sus parientes. Estos documentos son de una importancia fundamental (...)".

19. Maganto Pavón (2013: 20-21). Lucía Megías (2016: 58-70). 
Sevilla desempeñando su oficio de comisario, pueden clasificarse como excepcionales, pues facilitan información relevante sobre sus ocupaciones, tratos personales y relaciones profesionales entre febrero y abril de 1593, cuando Cervantes ya frisaba los 46 años de edad. Por su especial interés destacan los documentos que vinculan a Cervantes con una nueva figura femenina que, inesperadamente, aparece en la biografía de nuestro escritor: la bizcochera sevillana doña Magdalena Enríquez.

Del mismo modo, la documentación nueva y también inédita que hemos podido localizar posteriormente, proporcionan datos de carácter vital mucho más precisos sobre esta mujer, con la cual es muy probable que Cervantes hubiera mantenido una relación personal mucho más cercana, que rebasara el límite de lo estrictamente profesional o comercial, convirtiéndose en una relación más amistosa. Doña Magdalena Enríquez no solo formaría parte del importante entramado mercantil de la Sevilla de la Edad Moderna, cuyo centro neurálgico y de negocios se encontraba en el entorno de las gradas de la Catedral, la Real Casa de la Moneda y la Casa de la Contratación, cerca del Alcázar, lugares por donde también se movía Cervantes, sino que además era vecina y buena amiga del matrimonio formado por doña Mariana de Carvajal y Tomás Gutiérrez de Castro, el conocido comediante, posadero, protector y amigo personal de Miguel de Cervantes, en cuya posada encontró alojamiento nuestro comisario en más de una ocasión. Todos ellos con residencia contrastada en la misma calle Bayona (actualmente rotulada con el nombre de Federico Sánchez Bedoya, frente a la Catedral), donde compartieron amistades comunes $^{20}$.

Así pues, doña Magdalena se nos presentará como una destacada y acaudalada empresaria, dueña de uno de los más importantes hornos de Sevilla dedicados, casi en exclusiva, a la elaboración del bizcocho con el que se alimentaban los marineros y soldados que servían a Felipe II en las galeras de su Armada y en los galeones que escoltaban a las Flotas que partían hacía las Indias. De estas fábricas de pan salían ingentes cantidades de galleta o bizcocho, manufacturado con la harina resultante de la molienda del trigo que acopiaban los comisarios reales de abastos para su entrega a los tenedores de bastimentos, los funcionarios responsables de su almacenaje y distribución.

En esta documentación de los años 1593 y 1594, el nombre de doña Magdalena Enríquez aparecerá junto al de Miguel de Cervantes en tres ocasiones: en un asiento contable de la data de las cuentas presentadas en 1596 por Francisco de Agüero, pagador de la Real Armada, hoy conservadas entre los fondos del Archivo General de Indias, y en dos documentos (un poder especial y una carta de pago) hallados entre los libros de protocolos notariales de Sevilla que se custodian en el Archivo Histórico Provincial de la capital

20. Cabello Núñez (2016, en prensa). Durante mi intervención en la Mesa Redonda que bajo el título "Cervantes y Andalucía. Comisario al servicio de Su Majestad” se celebró en Écija (Sevilla) el 7 de noviembre de 2015, di a conocer algunos documentos inéditos sobre doña Magdalena Enríquez. 
hispalense, otorgados por Miguel de Cervantes y doña Magdalena Enríquez los días 8 de julio de 1593 y 28 de marzo de 1594, respectivamente, cuando aquél aún continuaba en el desempeño de su oficio de comisario real de abastos.

(DOC. I)

\section{3, marzo, 5 La Puebla de Cazalla (Sevilla)}

Carta de obligación. Otorgada por el Concejo, Justicia y Regimiento de la villa de La Puebla de Cazalla, comprometiéndose con el comisario real de abastos, Miguel de Cervantes Saavedra, a entregarle 130 fanegas de trigo y 20 fanegas de cebada para el aprovisionamiento de los galeones de escolta de la Flota de la Carrera de las Indias, cumpliendo lo ordenado por Cristóbal de Barros, su proveedor general. (Archivo de Protocolos Notariales de Morón de la Frontera, Sección de Escribanías de La Puebla de Cazalla) ${ }^{21}$.

Este valioso documento cervantino, descubierto entre los protocolos notariales de La Puebla de Cazalla y que llevó a la posterior localización de los demás, no sólo certifica la presencia de Miguel de Cervantes en este municipio de la provincia de Sevilla en los primeros días del mes de marzo de 1593, cuando sus biógrafos consideraban que se encontraba vacante y sin oficio conocido en la ciudad de Sevilla ${ }^{22}$, sino que además facilita información sobre la existencia de una comisión que hasta ahora era totalmente ignorada; ésta fue dada a Cervantes por Cristóbal de Barros y Peralta, el primer proveedor general en la Casa de la Contratación de Sevilla de los galeones de la Armada y Flotas de la Carrera de las Indias ${ }^{23}$, para que continuara prestando sus servicios al Rey Felipe II como comisario real de abastos. Es ésta una relación personal y profesional también inédita que necesariamente hemos de añadir

21. Publicado en Cabello Núñez (2014: 57-71). El documento original se conserva en el Archivo de Protocolos Notariales de Morón de la Frontera, Sección Escribanías de La Puebla de Cazalla, libro $n^{\circ}$ 149, año 1593, folios 25 r.- 26 v., escribanía de Pedro González de Villalba. Existen copias del documento, en microfilm y formato digital, en el Archivo Municipal de La Puebla de Cazalla, Colección Protocolos Notariales.

22. Zaragoza (1991: 234). Canavaggio (2005: 226-230). Fernández Álvarez (2005: 317-320). Tras el descubrimiento y edición de estos nuevos documentos cervantinos, Canavaggio ha rectificado lo publicado en 2005 respecto a las actividades desarrolladas por Cervantes en Sevilla durante los primeros meses de 1593, dejando constancia de esta documentación en la reedición de su biografía de Cervantes. Vid. Canavaggio (2015: 200).

23. Cristóbal de Barros y Peralta estuvo considerado como el mejor constructor de navíos de guerra del reinado de Felipe II, artífice de la organización técnica de la escuadra española vencedora en la Batalla de Lepanto y de la Gran Armada. Ostentó el cargo de Superintendente de Fábricas, Montes y Plantíos de la Costa Cantábrica y, tras ser nombrado fabricador mayor, pasó a Sevilla en el año 1592 como el primer proveedor general de la armada que daba escolta a los galeones de la Flota de la Carrera de las Indias, permaneciendo en la ciudad hispalense hasta su muerte, acaecida el 2 de mayo de 1596. Cabello Núñez (2015: 128-129). Martín Bartolomé (2014), disponible en la dirección Web: http://www.freewebs.com/ahanc/historia.htm. 
a las que mantuvo durante el desempeño de este empleo con el alcalde de la Real Audiencia de Sevilla, el licenciado Diego de Valdivia, y los proveedores generales Antonio de Guevara, Pedro de Isunza y Miguel de Oviedo.

Los datos ofrecidos en este acuerdo, alcanzado entre Cervantes y los regidores municipales de La Puebla de Cazalla, permitieron la posterior localización y acceso a otros cinco documentos, entonces igualmente inéditos, que en la actualidad se conservan entre los fondos del Archivo General de Indias y en la Sección de Protocolos Notariales del Archivo Histórico Provincial de Sevilla, que vienen a cubrir, en parte, una importante laguna documental que aún existe en la biografía de Cervantes, proporcionándonos información sobre el lugar de su residencia (Sevilla) y el desempeño de su actividad profesional en las villas y ciudades de su comarca que serían objeto de su visita en los primeros meses del año 1593, cuando se encontraba a las órdenes de Cristóbal de Barros.

\section{Transcripción}

1593, marzo, 5 La Puebla de Cazalla (Sevilla)

"// 25 r. (Al margen izquierdo: Miguel de Cerbantes comisario contra el concejo, fecho).

Sepan quantos esta escriptura bieren como nos el Licenciado Antonio de Caçorla, corregidor, y Juan de Soto alcayde de la fortaleça desta villa, Gonçalo de Luna, alcalde hordinario del estado delos hijosdalgo, Garcí Gonçalez Calero asimismo alcalde, Juan Muñoz de Salaçar alguacil mayor, Alonso de Angulo, Melchor de la Torre, Gonçalo Labado, regidores, Pedro García Venxumea, fiel y executor y Pedro Hormigo jurado, oficiales del concejo desta villa de La Puebla de Cazalla, estando juntos en nuestro cabildo e ayuntamiento, como lo abemos de costumbre, todos juntamente y de mancomún a boz de uno e cada uno de nos por si e por el todo ynsolidum, renunciando como renunciamos la lex de duobus reis devendi y el autentica presente cobdice de fidejusoribus y el beneficio de la dibision y escursión y las demas leyes e derechos de la mancomunidad como en ella se contiene, decimos que por quanto por horden y mandado de Christoval de Barros, probeedor de los galeones de la armada de Yndias, bino a esta villa Miguel de Cerbantes // 25 v. Sayabedra, comisario a sacar trigo de los vecinos desta villa para el probeymiento de los dichos galeones, para lo qual el dicho comisario a hecho sacar trigo de algunas casas desta villa y por ebitar el daño quel susodho puede hacer a los vecinos desta villa en sacar el dicho trigo somos convenidos y concertados con el dicho comisario que 
le demos ciento y treinta fanegas de trigo y veinte fanegas de cebada, con lo qual se contenta y satisfaçe de todo el repartimiento que en esta villa se podía hacer. Y teniéndolo por bien, por el tenor de la presente debaxo de la mancomunidad que tenemos fecha, otorgamos y conoçemos por esta presente carta que nos obligamos de dar e pagar al dicho Miguel de Cerbantes Sayabedra o a la persona que su poder ubiere, las dichas [tachado: treynta] ciento y treinta fanegas de trigo y veinte fanegas de cebada de las quales tiene recebidas las ocho fanegas de cebada, y se las daremos y entregaremos puestas en esta villa de La Puebla de Cazalla y a su fuero e jurisdicción todas juntas en una parte de buen trigo limpio enjuto de dar en ella bien medido con buena medida a nuestra costa, el sábado primero que biene que se contarán trece días deste mes de março y año de la fecha desta. Y si no lo diéremos y entregáremos según dicho es, que el dicho comisario lo pueda comprar de la parte donde lo hallare y por el precio y acarretos que le costaren le pueda executar con solo su juramento en que le diferimos; demás de lo qual nos obligamos de dar e pagar a la persona que viniere a la cobrança // $26 \mathrm{r}$. del dicho trigo y cebada. Y si no lo diéramos el dicho día como está declarado, seiscientos maravedíes cada un día de los que se ocupare en la cobranza dello de benida, estada y buelta, por los quales dichos salarios se nos pueda executar como por el principal con solo el juramento de la persona que a ello biniere en que lo diferimos. La qual dicha escriptura otorgamos en boz del concejo y en el nombre de él y el dicho comisario da y paga mill y novecientos y quarenta reales que monta todo el dicho trigo y cebada, los quales nos da y paga en presencia del escribano público e testigos de yuso escriptos del qual entrego yo el dicho escribano doy fee, excepto de lo que montan las ocho fanegas de cebada que tiene recebidas el dicho comisario en quenta de las veinte declaradas en esta escriptura. De todos los quales dichos maravedíes recibo yo el dicho Pedro Hormigo, jurado, para haçer pago a las personas de quien se sacare y repartiere el dicho trigo, los quales reçibo en presencia del presente escribano y testigos de yuso escriptos, de que yo el dicho escribano doy fee y para complir todo como dicho es nos obligamos los propios y rentas deste concejo abidos e por aber. E yo el dicho Miguel de Cerbantes Sayabedra comisario susodicho, que presente soy a lo contenido en esta escriptura, otorgo y conozco que la aceto en mi fabor y estoy contento y satisfecho con la cantidad de trigo y cebada contenida en esta escriptura, la qual recibiré el dicho día sábado trece deste mes siendo de la forma y manera questá declarado y no pediré más cantidad de la suso dicha so pena de le pagar las costas y gastos // 26 v. que en raçón de lo susodicho 
se les siguieren y recibieren. Y de las dichas ocho fanegas de cebada me otorgo por contento y entregado a mi boluntad sobre que renuncio las leyes de la entrega, prueba e paga como en ella se contiene. Y para lo cumplir obligo mi persona e bienes abidos e por aber, todos como dichos somos damos poder cumplido a las justicias del rey nuestro señor para que a ello nos apremien como por sentencia pasada en cosa juzgada y renunciamos las leyes de nuestra defensa y la general del derecho. En testimonio de lo qual otorgamos la presente, ante el escribano público y testigos de yuso escriptos, que es fecha en la dicha villa de La Puebla de Cazalla en cinco días del mes de março de mill y quinientos y nobenta e tres años, siendo testigos Pedro Gutiérrez Borrego y Alonso Ximenez Salteras y Alonso Martínez de Calvente, vecinos desta villa, y lo firmaron los que supieron y por los demás un testigo. A los quales otorgantes yo el escribano doy fee que conozco. Tachado treinta y enmendado, sanados. Juan de Soto (firma y rúbrica), licenciado Caçorla (firma y rúbrica), Gonzalo de Luna (firma y rúbrica), Juan Muñoz (firma y rúbrica), Alonso de Angulo (firma y rúbrica), Melchor de la Torre (firma y rúbrica), Gonzalo Lavado (firma y rúbrica, Pedro García Benjumea (firma y rúbrica), Pedro Hormigo (firma y rúbrica). Testigo Alonso Martínez de Calvente (firma y rúbrica). Ante mí, Diego Sánchez de Aguilera, escribano público (firma y rúbrica).

(DOC. II)

\section{6/ s.m./ s.d./ Sevilla}

Asiento contable en la data de las cuentas presentadas por Francisco de Agüero, pagador de la Real Armada en la Casa de la Contratación de Sevilla, justificativa de haber satisfecho al comisario Miguel de Cervantes los 19.200 maravedíes que se le debían por su salario de 48 días ocupados en sacar 998 fanegas de trigo, conforme a una libranza de pago de 9 de noviembre de 1593 firmada por el proveedor general Cristóbal de Barros. (Archivo General de Indias, Sevilla). ${ }^{24}$

El documento notarial de La Puebla de Cazalla permitiría el hallazgo en el Archivo General de Indias de un asiento contable referido a Miguel de Cervantes (el primero localizado en este Archivo relacionado con la comisión

24. Publicado en Cabello Núñez (2015: 134). El documento original se conserva en el Archivo General de Indias, Casa de la Contratación, Contratación, Leg. 3.313. Digitalizado en la Web Las rutas de Cervantes, disponible en la dirección web: https://www.google.com/culturalinstitute/beta/u/0/asset/-/1gG-nn_0raCdcA?childAssetId=MgE5Hgv7 9eSndQ. 
de Cristóbal de Barros). Se trata de una partida justificativa de otro de los numerosos pagos realizados entre los años 1593 y 1596 por Francisco de Agüero, pagador de la Real Armada en la Casa de la Contratación de Sevilla, para el aprovisionamiento de los galeones que escoltaban a las Flotas de la Carrera de las Indias, si bien esta anotación tiene la particularidad de contener el nombre de Miguel de Cervantes.

En el pliego número 28 del legajo donde se conservan algunas de las cuentas presentadas por Agüero en 1596, se ofrece una larga relación de pagos efectuados en virtud de las libranzas del proveedor Cristóbal de Barros, firmadas por éste entre los días 6 y 15 de noviembre de 1593, destacando una fechada el 9 de noviembre que ordenaba se pagasen 19.200 maravedíes a Miguel de Cervantes (Cerbantes en el original), comisario de la proveeduría, por el salario de cuarenta y ocho días que se ocupó en sacar 998 fanegas de trigo para la provisión de la Armada, a razón de 400 maravedíes diarios.

Este apunte de contabilidad nos permitía situar a Cervantes ejerciendo su labor de comisario real de abastos durante un amplio periodo de tiempo (48 días) y conocer las fanegas de trigo recogidas (998). Sin embargo, no facilitaba ningún otro dato que nos permitiera conocer aquellos meses en los que desempeñó la comisión cuyo salario iba a percibir; meses de trabajo que podrían haber coincidido con los de otras dos comisiones encomendadas por el proveedor general Miguel de Oviedo los días 7 de julio y 19 de agosto de 1593. El posterior hallazgo en el Archivo General de Indias de un tercer documento cervantino resolvería algunas de estas incógnitas.

\section{Transcripción}

\section{6 /s.m./ s.d./ Sevilla}

"// Pliego 28 [1 r.] (Al margen izquierdo: El dicho pagador Francisco de Agüero, la dicha su data de proveeduría, segundo pliego de noviembre 93) //

// 1 v. Por otra del dicho día ${ }^{25}$ a Miguel de Çerbantes comisario de // 2 r. la proveeduría, diez y nueve mill y dusientos maravedíes por su salario de quarenta y ocho días que se ocupó en sacar 998 fanegas de trigo para provisión de la Armada, a razón de quatroçientos maravedís al día $=19.200 "$ ".

(DOC. III)

1596, noviembre, 18. Sevilla.

25. Libranza del proveedor general Cristóbal de Barros, fechada en Sevilla el 9 de noviembre de 1593 . 
Asiento contable en la data de la cuentas presentadas por Francisco de Agüero, pagador de la Real Armada en la Casa de la Contratación de Sevilla, justificativa de haber satisfecho a doña Magdalena Enríquez, en nombre de Miguel de Cervantes, los 19.200 maravedíes que se le debían por su salario de 48 días que se ocupó en sacar 998 fanegas de trigo y 174 fanegas de cebada de algunos lugares de la comarca de Sevilla. (Archivo General de Indias, Sevilla) ${ }^{26}$.

El documento II nos encaminaría hacia la localización de este tercer documento (el segundo descubierto entre los fondos del Archivo General de Indias identificado con esta comisión) datado en Sevilla el 18 de noviembre de 1596. Esta nueva partida contiene valiosos datos que confirman, no sólo la fecha en la que Cervantes estuvo en La Puebla de Cazalla, sino también los días y meses concretos durante los cuales se dedicó a embargar trigo y cebada en la comarca de Sevilla, las fanegas de cereal que finalmente pudo conseguir y el salario recibido por su trabajo. Sin embargo, una lectura más atenta y detenida del mismo nos proporcionaría otros datos, igualmente nuevos e inéditos, que vendrían recogidos en un documento cervantino conservado en el Archivo Histórico Provincial de Sevilla. Se observará en el texto que no se indica que fuera Miguel de Cervantes quien recibiera personalmente el dinero que aún se le debía, sino que su salario fue cobrado por otra persona en su nombre, actuando en virtud de las facultades que Cervantes le había otorgado en un poder notarial firmado en Sevilla el 8 de julio de 1593, precisamente cuando estaba a punto de comenzar una nueva comisión, ahora bajo las órdenes del proveedor Miguel de Oviedo. Esa persona es una mujer, nombrada como doña Magdalena Enríquez, vecina de Sevilla y residente en la collación de Santa María, que por primera vez aparece vinculada con nuestro escritor.

En ella se hace constar fehacientemente que doña Magdalena Enríquez, en nombre de Miguel de Cervantes, era quien había recibido del pagador Francisco de Agüero los 19.200 maravedíes que le correspondían de salario por los cuarenta ocho días de servicios prestados como comisario, conforme a la comisión de 21 de febrero de 1593. Cervantes había salido de Sevilla el 21 de febrero y regresó a ella el 28 de abril, habiendo podido reunir tan sólo 998 fanegas de trigo y 174 fanegas de cebada. Por tanto, este nuevo documento se correspondía plenamente con aquella libranza de pago fechada el 9 de noviembre de 1593.

\section{Transcripción}

1596, noviembre, 18 Sevilla

26. Publicado en Cabello Núñez (2015: 139). En la página 137 de la citada publicación, existe una errata en la redacción de la frase "el día 18 de noviembre de 1593", pues en realidad debe decir "el día 18 de noviembre de 1596". El documento original se conserva en el Archivo General de Indias, Casa de la Contratación, Contratación, Leg. 3.313. Digitalizado en la Web Las rutas de Cervantes, disponible en la dirección https://www.google.com/culturalinstitute/beta/asset/-/oAF_ltHwrsyUHA?ch ildAssetId=wwHll_6wH5Xw0g. 
"// Pliego 152 [2.r] Yten diez y nuebe mill y doçientos maravedís que por librança del dicho probeedor Christoval de // $\mathbf{2}$ v. Barros en la dicha çiudad de Sevilla, a nuebe de noviembre de quinientos y nobenta y tres, tomada la razón por Françisco Negrete y Francisco de Ayzpuru, que servían el ofiçio de veedor y contador de la dicha Armada, pagó a doña Magdalena Enrríquez, vezina de la dicha çiudad en nombre de Miguel de Çerbantes Saabedra, comisario vecino de la dicha çiudad, y por virtud del poder que del hubo, que pasó ante Alonso de Cívico, escribano público en ocho de julio de quinientos y nobenta y tres, que los hubo de hauer por su salario de quarenta y ocho días que por orden del dicho probeedor se ocupó, en virtud de la comisión que le dio en veinte y uno de hebrero del dicho año, en sacar de algunos lugares de la comarca de la dicha çiudad, nobeçientas y nobenta y ocho fanegas de trigo y çiento y setenta y quatro fanegas de çebada para los harrieros y bagajes que lo conduçieron (sic) el dicho trigo a la dicha çiudad de Sevilla para fabricar vizcocho para la dicha Armada, desde el dicho día veinte y // Pliego 153 [1 r.] uno de hebrero que salió desta çiudad de Sevilla, hasta veinte y ocho de abril siguiente, ynterpolados a razón de quatroçientos maravedís al día, como paresçió de la quenta que dello se le tomó y testimonios que presentó que quedaron en los libros de la dicha probeeduría, como paresçe por la dicha librança y comisión y poder y carta de pago que dio del resçivo de los dichos maravedís en la dicha çiudad de Sevilla, a diez y ocho de noviembre de quinientos y ochenta y seis (sic) y paresçe auerse pagado con ynterbençión del dicho Francisco Negrete."

(DOC. IV)

1593, julio, 8 Sevilla

Carta de poder especial. Otorgada por Miguel de Cervantes Saavedra a favor de doña Magdalena Enríquez, bizcochera de Sevilla, para que durante su ausencia pudiera cobrar los maravedíes que se le debían de salario por su ocupación como comisario real de abastos al servicio de Cristóbal de Barros. Consta la firma autógrafa de Cervantes. (Archivo Histórico Provincial de Sevilla, Protocolos Notariales de Sevilla) ${ }^{27}$.

27. Publicado en Cabello Núñez (2015: 141-142). El documento original se conserva en el Archivo Histórico Provincial de Sevilla, Sección Protocolos Notariales de Sevilla, Sig, 5.423, Oficio $\mathrm{n}^{\circ}$ 8, protocolo del escribano público Alonso de Cívico, año 1593, Fol. 472 r.- 472 v. El documento se encuentra muy deteriorado por la acidez de las tintas empleadas en su redacción. 
El cuarto documento cervantino (el primero de los hallados en el Archivo Histórico Provincial de Sevilla relacionados con la comisión de 21 de febrero) destaca entre todos los demás por dos importantes singularidades: contiene la firma autógrafa de Cervantes (quien lo hace como Miguel de Cerbantes Saa vedra) y el nombre de una mujer, doña Magdalena Enríquez, que por vez primera se vincula con nuestro comisario. Este interesante testimonio es un poder especial que Cervantes otorga ante escribano público para que, durante su ausencia, doña Magdalena pudiera cobrar el salario que el proveedor general Cristóbal de Barros aún le debía. Mientras los pagadores de la Armada en la Casa de la Contratación de Sevilla revisan las cuentas presentadas por Cervantes tras concluir su trabajo a las órdenes de aquél proveedor, nuestro comisario se apresta para salir de viaje y comenzar la nueva comisión que un día antes le había encomendado Miguel de Oviedo, el proveedor general de las galeras de España, para que sacara todo el trigo que pudiese de los lugares, villas y ciudades que se encontrasen en un contorno de doce leguas de distancia de Sevilla ${ }^{28}$.

\section{Transcripción}

\section{3, julio, 8 Sevilla}

// 472 r. "Sepan quantos esta carta vieren como yo Miguel de Çerbantes Saabedra, comisario del rey nuestro Señor, estante en esta ciudad de Sevilla, otorgo y conozco que doy todo mi poder cumplido quan bastante de derecho se requiere y es necesario, a doña Magdalena Enríquez, vecina desta dicha ciudad de Sevilla, en la collación de Santa María, especialmente para que por mí y en mi nombre pueda pedir e demandar e recibir y cobrar (...) de la Real Audiencia del rey nuestro Señor y de Christoval de Barros, proveedor de su Real Armada del cargo del general don Francisco de Coloma y de otro cualquier tesorero e proveedor o persona que le hubiere de pagar e de sus bienes, y de quien con derecho deba, todo lo que se me hubiere de haber de mi salario por los derechos y tiempo que me ocupé en sacar trigo para el servicio de Su Majestad por orden e comisión del dicho proveedor Christoval de Barros este presente año de quinientos y noventa e tres, y del recibo de ello pueda dar y otorgar sus cartas y albalaes de pago, finiquitos, poder e lasto y otras que convengan y valgan como si yo las otorgase siendo (...) e si el dicho entrego no fuere ante escribano que de fe, renunciar la ex- 
cepción e leyes de la non numerata pecunia e prueba de la paga, e recibir como en ella se contiene en razón de la dicha cobranza, siendo necesario pueda parecer ante cualquier justicias que con derecho deba y hacer todas las demandas y pedimentos e requerimientos, protestaciones, emplazamientos, citaciones, entregas, execuciones, prisiones, consentimientos de solturas, embargos e desembargos, secuestros, ventas [roto] remates de bienes e los juramentos que convengan y hacer e haga en juicio y fuera del todos los demás autos e diligencias judiciales y extrajudiciales que convengan e menester sean de se hacer e pasarlas // 472 v. hacer podría, siendo que para todo e a ello dependiente le doy tan cumplido poder como de derecho se requiere con libre e general administración en lo susodicho y con facultad que lo pueda sustituir en quien quisiere y revocar los sustitutos e nombrar otros y a todos les pedir cuentas, e cobrar de ellos lo que entrare en su poder e darles cartas de pago y a todos recibo en fe de escribano. E para la firmeza de ello obligo mi persona e bienes habidos e por haber. Fecha en la ciudad de Sevilla a ocho días del mes de julio de mil e quinientos e noventa e tres años, y el dicho otorgante que yo el presente escribano público doy fe que conozco lo firmó de su nombre siendo testigos Alonso de Tineo e Christoval de Flores, escribanos de Sevilla. Miguel de Cerbantes Saavedra (firma y rúbrica); Christoval de Flores, escribano de Sevilla (firma y rúbrica); Alonso de Tineo, escribano de Sevilla (firma y rúbrica); Alonso de Çíbico, escribano público de Sevilla (firma y rúbrica); Derechos: cinco reales."

\section{(DOC. V)}

\section{3, noviembre, 9 Sevilla}

Libranza del proveedor general Cristóbal de Barros, por la cual se ordena pagar a Miguel de Cervantes 19.200 maravedíes, salario que le correspondía por los 48 días que se ocupó en la comisión de 21 de febrero de 1593. (Archivo General de Indias, Sevilla) ${ }^{29}$.

El quinto documento (el tercero de los hallados en el Archivo General de Indias sobre esta comisión) es la libranza de pago firmada por Cristóbal de

29. Publicado en Cabello Núñez (2015: 143). En la citada publicación existe un error en la transcripción del documento, pues donde dice "nobeçientos y setenta y quatro fanegas de trigo" ha de decir "nobeçientas y noventa y ocho fanegas de trigo", subsanándose en esta edición. El Documento original se conserva en el Archivo General de Indias, Casa de la Contratación, Contratación, Leg. 3.314. Documento digitalizado en la Web Las rutas de Cervantes, disponible en la dirección https://www. google.com/culturalinstitute/beta/u/0/asset/-/2AEPrl2xfCL_tg?childAssetId=RQHU1BmCxLDt0A. 
Barros el 9 de noviembre de 1593. Por ella se autoriza a Francisco de Agüero, pagador de la Real Armada, para satisfacer al comisario Miguel de Cervantes los 19.200 maravedís que le correspondían por su salario de 48 días (del 21 de febrero al 28 de abril de 1593) que estuvo sacando trigo y cebada de diversos lugares de la comarca de Sevilla para el abastecimiento de la Armada. En el mismo documento, a continuación de la libranza, consta la copia certificada del texto íntegro de la comisión de Cristóbal de Barros, fechada en Sevilla el 21 de febrero de 1593, donde se relacionan los lugares que deberían ser visitados por Cervantes y el bizcochero Juan Sáenz de la Torre.

\section{Transcripción}

\section{3, noviembre, 9 Sevilla}

// Fol. s/n [1 r.] (Al margen superior izquierdo: "A Miguel de Çerbantes Saabedra, comisario de la proveeduría. 19.200 maravedís, que se le libran por su salario de 48 días que se ocupó en sacar 998 fanegas de trigo y cebada para la Armada, a razón de 400 maravedís al día. Año 1593.”)

(Al margen superior derecho: "Fecha en Sevilla a 9 de noviembre de 93 . No resulta cargo y en data”).

"Francisco de Agüero, pagador por el Rey nuestro Sr. de su Armada Real de la Guardia de las Yndias de los maravedís de su cargo, de v.m. y pague a Miguel de Çervantes Sahabedra, comisario vecino desta çiudad o a quien su poder hubiere, diez y nueve mil y duçientos maravedís que se los libro y los ha de haber de su salario de quarenta y ocho días que por mi orden se ocupó, en virtud de la comisión que le dí en veinte y uno de febrero deste año, cuya copia va con esta librança, en sacar de algunos lugares de la comarca desta çiudad nobeçientas y noventa y ocho fanegas de trigo y çiento y setenta y quatro fanegas de çebada para los arrieros y bagajes que los conduçieron (sic) por el dicho trigo a esta çiudad para fabricar bizcocho para provisión de la dicha Armada, desde dicho día veinte y uno de febrero que salió desta çiudad, hasta veinte y ocho de abril siguiente, interpolado a raçón de a quatroçientos maravedís al día como pareçe de // 1 v. la quenta que dello se le tomó y testimonios que presentó que quedan en los libros de mi oficio, y tome su carta de pago, con la cual y la dicha [tachado: carta de pago] copia de la dicha comisión questá firmada de Juan Sayz de Egoen mi secretario y esta librança, tomando la raçón della Francisco Negrete que açe oficio de veedor por el Sr. don Luis Fajardo, veedor que es de la dicha Armada, 
con cuya interbençión se ha de açer la dicha paga y tomándola Francisco Yzpurun que açe oficio de contador por el señor Agustín de la Guerra, les serán reçibidos y pasados en quenta los dichos diez y nueve mil y duçientos maravedís, fecha en Sevilla en 9 de nobienbre de 1593. Christoval de Barros" (firma y rúbrica).

(DOC. VI)

$$
\text { 1593, febrero, } 21 \text { Sevilla }
$$

Comisión que el proveedor general Cristóbal de Barros da al comisario Miguel de Cervantes Saavedra, inserta en la libranza de pago de 9 de noviembre de 1593, para que acompañado de Juan Sáenz de la Torre, bizcochero de Sevilla, vaya a las villas de Carmona, Utrera, Arahal, Morón de la Frontera, La Puebla de Cazalla, Marchena, Paradas, Osuna, Villamartin y otros lugares de Andalucía, para sacar trigo, cebada y otros bastimentos para la provisión de los galeones de la armada que daba escolta a las Flotas de la Carrera de las Indias. (Archivo General de Indias, Sevilla) ${ }^{30}$.

El sexto documento cervantino (el cuarto de los descubiertos en el Archivo General de Indias) es una copia certificada de la comisión que el 21 de febrero de 1593 encomendó el proveedor general Cristóbal de Barros al comisario Miguel de Cervantes. Expedida el mismo día de su firma por Juan Sáenz de Egoen, el secretario personal del proveedor, está inserta en el documento que contiene la anterior libranza de 9 de noviembre de 1593.

Es esta nueva comisión, hasta ahora desconocida en la biografía de Cervantes, la primera y única, que sepamos, le fuera encomendada por Cristóbal de Barros. En ella se deja ordenado que, llevando vara alta de Justicia y acompañado de Juan Sáenz de la Torre, un bizcochero vecino de Sevilla con el que Cervantes también aparece relacionado por vez primera, visitase las villas de Carmona, Utrera, Arahal, Morón de la Frontera, La Puebla de Cazalla, Marchena, Paradas, Osuna y Villamartín, así como otros lugares de Andalucía que le pudieran convenir, hasta conseguir 5.000 fanegas de trigo para la fabricación de bizcocho, 500 fanegas de cebada para los arrieros, 400 fanegas de garbanzos, 400 fanegas de habas y 300 quintales de queso para el abastecimiento de los galeones de la Armada que escoltaban a las Flotas de la Carrera de las indias. No podría Cervantes cumplir el objetivo marcado, pues tan sólo pudo conseguir 998 de las 5.000 fanegas de trigo que se necesitaban.

El proveedor consideraba a Cervantes una persona inteligente y de confianza para cumplir la misión que se le encargaba y exime de la obligación

30. Publicado en Cabello Núñez (2015: 144-146). El documento original se conserva en el Archivo General de Indias, Casa de la Contratación, Contratación, Leg. 3.314. Documento digitalizado en la Web Las rutas de Cervantes, disponible en la dirección https://www.google.com/culturalinstitute/ beta/u/0/asset/-/iwFH-q3skkCahQ? childAssetId=PQGzxQze9S32Cw. 
de entregar el cereal a las personas pobres y que tuviesen poco pan. Esta comisión permite poder documentar nuevas visitas personales de Cervantes a las ciudades y villas de Carmona, Utrera, Arahal, Marchena y Paradas ${ }^{31}$ que también eran desconocidas, pudiendo considerarse como el primer documento oficial de la época donde las localidades de La Puebla de Cazalla, Osuna, Morón de la Frontera y Villamartin, aparecen citadas como lugares objeto de la visita personal de Miguel de Cervantes. La búsqueda de documentación en sus archivos municipales y de protocolos notariales, centrada en los cuarenta y ocho días durante los cuales se desarrolló esta nueva comisión, podrían confirmar si la visita del comisario Cervantes a esos lugares tuvo o no lugar $^{32}$. Tras la publicación de este nuevo documento cervantino, el archivero municipal e investigador local del municipio de Los Palacios y Villafranca (Sevilla), Julio Mayo Rodríguez, pudo documentar esta nueva presencia de Cervantes en Utrera gracias al hallazgo de un poder notarial con su firma autógrafa, fechado el 29 de marzo de 1593, que se conserva entre los protocolos notariales utreranos ${ }^{33}$.

\section{Transcripción}

\section{3, febrero, 21 Sevilla}

// Fol s/n [1 v.] "Christoval de Barros, Señor de la uilla de Nauares de las Cuebas a cuyo cargo es por mandado del rey nuestro señor la fábrica general de las naos y nauíos destos reygnos y la prouisión de la Real Armada dela Guarda de las Yndias, etc.

Conuiniendo al seruicio de Su Majestad y a la prouisión y despacho de la dicha Armada fabricar cantidad de uizcocho de trigo de la tierra para el sustento de la gente de mar y guerra que en ella ha de seruir, es necesario sacar el dicho trigo de que se fabrique de las partes y lugares donde lo haya y cómoda y breuemente se pueda conduçir a esta çiudad: para el dicho efecto y para que con el conduçirlo se haga con mas aprouechamiento de la Real Hacienda y los arrieros lo puedan traer, conuiene sacar cantidad de zeuada y para ello es necesario que haya persona ynteligente y

31. Estas villas y ciudades ya fueron visitadas por Cervantes con anterioridad: Carmona (años 1588 y 1590), Utrera (1592), Arahal (1592), Marchena (años 1588, 1590 y 1592) y Paradas (1588). Alcaide Aguilar (2009: 105-119).

32. La presencia de Cervantes en La Puebla de Cazalla (Sevilla) está plenamente confirmada el día 5 de marzo de 1593. Cabello Núñez (2014: 57-71).

33. Mayo Rodriguez (2015: 1-7). El documento original se conserva en el Archivo Histórico Provincial de Sevilla, Sig, 21.404-P, Oficio 8, protocolo del escribano público Martín Hernández Santiago, año 1593, Fol. 239 vto. 
de confianza que con todo cuidado haga lo suso dicho, y teniendo satisfacción de la de Miguel de Zerbantes Saauedra, vecino desta ciudad, le doy comisión, ordeno y mando que lleuando y traiendo bara alta // 2 r. de Justiçia de Su Majestad, baya a las villas de Carmona, Utura, el Haraal, Morón, La Puebla de Cazalla, Marchena, Paradas, Osuna, Villamartin y a las demás ciudades, villas y lugares del Andalucía que conuenga y sea necesario y le pareçiere, juntándose con Juan Sanz de la Torre vecino desta çiudad que entiende por comisión mía fecha en nueue deste mes en sacar este trigo y acerlo conduçir para que se enuargue, saque y conduzga çinco mill fanegas de trigo que son neçesarias de presente para la fabrica del dicho vizcocho, las quales y la zeuada ha de reçeuir, pagar y encaminar el dicho Juan Sanz de la Torre, lo qual se ha de repartir en las dichas villas y en otras qualesquier la cantidad que haçe y al dicho Juan Sanz de la Torre les pareciere y bien visto les fuere, escusando las personas pobres y que tienen poco pan, teniendo consideración a que se haga con breuedad y pagándoles a catorce reales la fanega ques conforme a la tasa de $\mathrm{Su}$ Majestad, y a las personas de quien lo tomare y reçiuiere el dicho Juan Sanz de la Torre antes que lo saque de los lugares donde lo tomare de quien tomará carta de pago en forma ante escriuano, y ansimismo sacará para dar a los arrieros que ouieren de conduçir el dicho trigo quinientas fanegas de zeuada que tanuién envargará y sacará en las dichas partes o en otra qualquiera donde las hallare, pagándole a sus dueños antes que las saque del lugar donde estubiere a seis reales cada fanega, que al preçio que por la prematica real está tasada, y para conduzirlo pueda enuargar todas las requas de arrieros y carretas y otros vagajes que tubieren neszesidad de la forma y manera que bien le pareciere, a los quales pagará sus portes el dicho Juan Sanz de la Torre a justos y moderados preçios, dándoles y repartiendo en ellos de la ceuada que tomaren la que le pareziere que bastara, contándoselas al dicho preçio de seis reales por fanega, y asimismo para que enuargue en las dichas partes quatrocientas fanegas de garbanço y otras quatrocientas de aua y trescientos quintales de queso, y para que ponga en parte segura y donde esté de manifiesto para que quando yo ordenare y mandare se traiga y conduzga y pague, que para todo lo suso dicho y cada cosa y parte dello todo y lo a ello // $2 \mathrm{v}$. anexo y dependiente le doy poder comisión en forma tan bastante como conuenga y sea necesario en uirtud de la que yo tengo del rey nuestro Sr. cuyo nombre mando y de mi parte exorto y requiero a todas y qualesquier Justiçias destos reygnos a cada uno en su juridiçión, le den el fauor y ayuda que le pidiere y ouiere menester para lo suso dicho, y siendo necesario se junten con él a 
haçer las calas y catas que conuengan hasta hallar el dicho trigo, ceuada, garbanço, aba y queso, y ansimismo mando a todas y qualesquier personas de qualquier estado, calidad y condición que sean, le den el fauor y ayuda que les pidiere y ouiere menester so las penas que les pusiere, las quales les he por y npuestas y en ellas por condenados lo contrario haçiendo, y que las pueda executar en sus personas y vienes el dicho Miguel de Servantes Saavedra, y mando a todos los escrivanos y alguaçiles de qualquier parte que sean, que usen y executen sus ofizios en lo que çerca de lo suso dicho les ordenare y mandare, y a los carçeleros que tengan en guarda y custodia los presos que les entregare y dellos den quenta quando el suso dicho la pidiere y lo hagan y cumplan so las dichas penas y el salario que ouiere de auer, buelto que sea a esta çiudad yo se lo mandaré tasar y pagar conforme a la ocupaçión y trauajo que ouiere tenido. Fecho en Seuilla a veinte y uno de febrero de mill e quinientos y nouenta y tres años. Christoval de Barros. Por mandado de su merced, Juan Sánz de Egoen" (firma y rubrica).

(DOC. VII)

\section{4, marzo, 28 Sevilla}

Carta de pago. Otorgada por doña Magdalena Enríquez, bizcochera de Sevilla, a favor de Francisco de Agüero, pagador de la Real Armada de la Guarda de las Indias, acreditativa de haber recibido, como cesonaria que era del comisario Miguel de Cervantes, los 19.200 maravedís que se le debían por su salario de 48 días en los que estuvo prestando servicios al proveedor general Cristóbal de Barros. (Archivo Histórico Provincial de Sevilla, Protocolos Notariales de Sevilla) ${ }^{34}$.

El séptimo de los documentos cervantinos, igualmente nuevo e inédito, es uno más de los numerosos justificantes emitidos para acreditar el pago de los gastos realizados en la comisión de 21 de febrero de 1593, tratándose del segundo directamente relacionado con aquella que pude descubrir entre los fondos del Archivo Histórico Provincial de Sevilla. Es una carta de pago otorgada por doña Magdalena Enríquez, la bizcochera sevillana a quien Cervantes había dado un poder notarial para que durante su ausencia cobrase el

34. El documento, aunque inédito hasta ahora, fue dado a conocer durante mi intervención en la Mesa Redonda que bajo el título Cervantes y Andalucía. Comisario al servicio de Su Majestad, se desarrolló en Écija (Sevilla) el 7 de noviembre de 2015. Vid nota 20. El original se conserva en el Archivo Histórico Provincial de Sevilla, Sección Protocolos Notariales de Sevilla, Sig. 5.424, Oficio $\mathrm{n}^{\circ}$ 8, protocolo del escribano público Alonso de Cívico, año 1594, Fol. 943 r.- 943 v. Se encuentra en mal estado de conservación, con importantes daños ocasionados por la tinta empleada para su redacción. 
salario que se le debía. Este testimonio que publicamos y transcribimos aquí en primicia, donde figura el nombre de Miguel de Cervantes en dos ocasiones, proporciona datos cruciales para adentrarnos en la vida de esta mujer cuya existencia era, hasta ahora, totalmente desconocida en la biografía cervantina y con la cual nuestro escritor se vincula por vez primera.

La carta de pago, otorgada por doña Magdalena Enríquez ante el escribano público Alonso de Cívico, acredita que ya había cobrado de la Casa de la Contratación de Sevilla los 19.200 maravedíes que se le debían a Miguel de Cervantes por los servicios prestados al proveedor Cristóbal de Barros. Está firmada, y he aquí un dato de especial relevancia e interés, por doña Magdalena de su propio puño y letra; fechada en Sevilla el 28 de marzo de 1594, es decir, ocho meses después de recibir de nuestro escritor aquel poder notarial de 8 de julio de 1593, prácticamente un año después de haber concluido Cervantes su comisión. Vista la fecha de su otorgamiento, inevitablemente surgen las preguntas: ¿Dónde se encontraba Cervantes mientras Magdalena cobraba el salario y otorgaba la carta de pago? ¿A qué se dedicaba Cervantes entre el 8 de julio de 1593 y el 28 de marzo de 1594 ?

Los documentos oficiales acreditan que Miguel de Oviedo, el proveedor general de las galeras de España, había comisionado a Cervantes el 7 de julio de 1593 para conseguir todo el trigo que pudiera hallar en los municipios situados doce leguas a la redonda de Sevilla, señalando expresamente las villas de Gerena, Almonte, El Puerto, Rociana, Bonares, Niebla, Lucenilla, Beas, Hinojos, Bollullos, Manzanilla, Escacena, Huevar, Castilleja del Campo, Alcalá de Guadaíra, Paterna, La Palma, Villamanrique y Villarrasa, en algunas de los cuales quedó constancia cierta de su visita. Del mismo proveedor recibiría otra comisión el 19 de agosto de 1593 para sacar 16.000 fanegas de trigo de las villas extremeñas de Llerena y Villagarcía ${ }^{35}$, perdiéndose el rastro de Cervantes durante cinco meses, desde el 16 de febrero de 1594, cuando está sacando trigo en la villa de Gerena (Sevilla), hasta el 1 de julio de ese mismo año, fecha en la que volvemos a tener noticias suyas en Madrid, donde había acudido para presentarse ante el licenciado Diego de Tamayo, teniente de corregidor de la Villa y Corte, con el fin de presentar a Francisco Suárez Gasco como fiador suyo para garantizar el cumplimiento de una nueva comisión recibida por Cervantes, esta vez no como comisario real de abastos, sino como recaudador de casi dos millones y medio de maravedíes que, en concepto de impuestos y tributos atrasados (alcabalas y tercias reales), se debían a la Corona en el Reino de Granada. Entonces declaró no ser ya vecino de Sevilla, sino de Esquivias y residente en Madrid.

Al analizar con más detenimiento el texto de esta novedosa carta de pago, nos llamaría poderosamente la atención que doña Magdalena reconoce haber recibido los 19.200 maravedíes que se debían a Cervantes en calidad 
de cesonaria ${ }^{36}$, esto es, como receptora de este derecho que se le cede. Ante esta información, cabría preguntarse cuáles fueron las razones que llevaron a Cervantes a confiarle el cobro de esta importante cantidad de dinero, fruto de dos meses de trabajo. ¿Sería doña Magdalena la destinataria final de estos maravedíes, recibidos como un pago a cuenta de una deuda de mayor cuantía que Cervantes pudiera mantener con ella, contraída por la compraventa de algún producto - bizcocho quizás-, o doña Magdalena tan sólo se constituía en su depositaria temporal hasta que aquel regresase de sus comisiones, recibiendo de ella ese dinero más tarde? ¿Pudiera tratarse, quizás, de la devolución de parte de un préstamo personal que le hubiera hecho doña Magdalena, o bien de una fianza que ésta depositara para responder de las obligaciones de Cervantes durante el ejercicio de su cargo?

Si se trataba del adelanto del pago de una deuda de mayor cuantía, originada por la compraventa de algún producto de consumo (bizcocho, por ejemplo), lo más probable es que esta relación de carácter comercial hubiera quedado plasmada en un documento contractual que jurídicamente comprometiera a ambas partes, como así consta en infinidad de documentos de similares características que se conservan en los archivos de protocolos notariales españoles. Por el contrario, si la relación era más personal, de amistad y de extrema confianza, es muy probable que no hubiera sido necesario redactar documento público alguno, bastando tan solo la palabra de ambos para la concesión y devolución del préstamo.

En el caso de que se tratara de la devolución de parte de una fianza o préstamo, ¿por qué solicitárselo a esta mujer, cuando Cervantes tenía buenos amigos y conocidos en Sevilla que ya en ocasiones anteriores se los facilitaron? Sirvan de ejemplo los realizados por Gómez de Carrión en diciembre de 1585; Juan de Nava Cabeza de Vaca y Luis Marmolejo, el 12 de junio de 1588; el posadero y buen amigo Tomás Gutiérrez de Castro, en junio de 1589, o el también bizcochero Juan de Jódar, el 7 de julio de $1593^{37}$.

Son todas ellas cuestiones a tener muy en cuenta, pues Miguel de Cervantes, en el poder otorgado a doña Magdalena el 8 de julio de 1593, no ofrece ninguna explicación, ni tampoco expone razón alguna que pudiera justificar plenamente esta cesión de su salario a favor de doña Magdalena. No sería del todo descabellado considerar que la única razón de dicha cesión no fuese otra que poder garantizar así, gracias a la mediación y gran influencia que doña Magdalena ejercía entre los funcionarios de la Casa de la Contratación de Sevilla, un rápido y efectivo cobro de su sueldo, el cual posteriormente

36. Acepciones de esta palabra en el Diccionario de Autoridades (1726-1739), Tomo II (1729). "Cessionario: la persona en cuyo favor se hace la cessión", disponible en la Web de la Real Academia Española de la Lengua: http://web.frl.es/DA.html; en la Enciclopedia Jurídica (2014), “Cesionario: La persona a cuyo favor se hace la cesión de bienes, el traspaso de un crédito o la transmisión de cualesquiera otros derechos", disponible en la dirección Web: http://www.enciclopedia-juridica.biz14. com/d/cesionario/cesionario.htm.

37. Sliwa 2015. 
recibiría Cervantes de estas manos femeninas cuando hubiera regresado de sus comisiones, evitando de este modo más trámites burocráticos.

No cabe duda que Cervantes era sabedor que doña Magdalena gozaba de gran estima, prestigio e influencia entre algunos de los jueces, oficiales y pagadores de la Casa de la Contratación, con los cuales incluso mantuvo negocios particulares. Así pues, aprovechándose de estas circunstancias y de su más que segura amistad con ella, nuestro comisario podría conseguir que el cobro de su salario no se dilatase mucho en el tiempo, como era lo más habitual, y simultáneamente que ese dinero estuviese a buen recaudo en buenas y seguras manos, mientras continuaba ejerciendo su labor de comisario en la nueva comisión que Cervantes, el mismo día 8 de julio de 1593, se aprestaba a iniciar en la comarca de Sevilla. En cualquier caso, aún no hemos podido localizar documento alguno que permita confirmar nuestras hipótesis.

¿Qué otra información de interés sobre doña Magdalena Enríquez, además de estas interesantes interrogantes, nos aporta el nuevo texto cervantino? Primeramente, que la otorgante deja constancia de tres datos de carácter personal que son fundamentales para poder adentrarnos en su vida: el estado civil (casada con Cristóbal Bermúdez desde al menos el 11 de agosto de 1589), el lugar de su residencia (en la collación de Santa María, en el entorno de la Catedral) y su nivel de formación o educativo (dice que sabe firmar y lo hace de su puño y letra, algo poco frecuente entre las mujeres de su época).

Toda esta información de carácter vital ya nos ha facilitado el acceso a un buen número de documentos del Archivo General de Indias y del Archivo Histórico Provincial de Sevilla, los cuales, una vez analizados e interrelacionados, me permiten poder afirmar, prácticamente sin ningún género de dudas, que entre Miguel de Cervantes y doña Magdalena Enríquez hubo una relación personal que fue mucho más allá de la estrictamente profesional o comercial, pudiendo incluirla en el círculo de amistades íntimas que Cervantes cultivaría durante su larga estancia en Sevilla y que ambos compartieron, especialmente en los ambientes próximos a la Catedral, junto a las Gradas, y cercanos al Arenal, el puerto de Sevilla, donde también tenía su residencia su gran amigo, el cordobés Tomás Gutiérrez de Castro, comediante y dueño de una de las más conocidas, prestigiosas y suntuosas posadas de la ciudad de Sevilla, sita en la entonces calle Bayona (hoy rotulada como Federico Sánchez Bedoya), del que también hemos podido confirmar sus vínculos de estrecha amistad con doña Magdalena Enríquez ${ }^{38}$. Gracias a estos y otros documentos, todos ellos aún inéditos, que aportan datos de gran interés para poder adentrarnos en el estudio de su vida, especialmente de sus actividades mercantiles y relaciones personales, se irán desvelando algunos de los enigmas que rodean a este nuevo personaje femenino que vendría a cruzarse en la vida de Cervantes.

\section{Transcripción}

38. González Aurioles (1912: 41 y apéndice). 


\section{4, marzo, 28 Sevilla}

// 943 r. "Sepan quantos esta carta vieren como yo doña Magdalena Enrríquez, mujer de Christoval Bermúdez, vezina que soy desta ciudad de Sevilla en la collación de Santa María, en virtud del poder y licencia fecha en esta que tengo del dicho mi marido, que pasó ante el presente escribano público en once días del mes de agosto de mil e quinientos e ochenta e nueve años a que me refiero, otorgo e conozco que he recibido he recibí de Francisco de Agüero, pagador por el rey nuestro señor de su Real Armada de la Guarda de las Indias, que está ausente, diez y nueve mill e doscientos maravedís, los quales me paga en virtud de una libranza del proveedor Christoval de Barros, dada sobre el dicho Francisco de Agüero para que pague los dichos maravedís a Miguel de Cervantes Saavedra, comisario comisario (sic) vezino desta ciudad, por la causa y razón que se declara en la dicha libranza que su fecha es a nueve de noviembre de mill e quinientos e noventa e tres años, que yo he de haber los dichos maravedíes como cesonaria que soy del dicho Miguel de Cervantes en virtud del poder y el suyo que me otorgó ante el presente escribano público en ocho días del mes de julio de mill e quinientos e noventa e tres años a que me refiero, los quales dichos diez y nueve mill y doscientos maravedís he recibido del dicho pagador Francisco de Agüero en reales de contado y son en mi poder, de que estoy contenta, pagada y entregada a mi voluntad, sobre que renuncio la exención e leyes de la yn numerata pecunia e prueba de la paga e recibo como en ella se contiene, en firmeza de lo qual otorgué la presente que es fecha la carta en Sevilla en veinte y ocho días del mes de marzo de mil e quinientos e noventa y quatro años y la dicha otorgante, que yo el escribano público yuso escrito doy fe que conozco, lo firmó // 943 v. de su nombre siendo testigos Juan de Valencia y Gerónimo de Cívico, escribanos de Sevilla. D. Magdalena Enrríquez (firma y rúbrica); Jerónimo de Cívico, escribano de Sevilla (firma y rúbrica); Juan de Valencia, escribano de Sevilla (firma y rúbrica); Alonso de Çíbico, escribano público de Sevilla (firma y rúbrica). 
MIGUEL DE CERVANTES SAAVEDRA, COMISARIO REAL DE ABASTOS EN PORCUNA (JAÉN). DOCUMENTOS VIII AL XIV

Los restantes documentos cervantinos que aportamos a continuación son nuevos e igualmente inéditos. Estos siete testimonios, localizados por mí entre los protocolos notariales del Archivo Histórico Provincial de Sevilla, forman parte de la serie que fue generada durante la comisión que Pedro de Isunza, el proveedor general de las galeras de España, encargara el 1 de octubre de 1591 a los comisarios reales de abastos Diego de Ruy Sáenz y Miguel de Cervantes para que llevando vara alta de Justicia y, por tanto, con los más amplios poderes, pudieran acopiar diversos bastimentos en una extensa relación de lugares del antiguo obispado de Jaén para el aprovisionamiento de las galeras reales. Entre ellos se encontraba la villa jiennense de Porcuna, vinculada a la Orden Militar de Calatrava desde el siglo XIII hasta los inicios del XVI. Sobre esta localidad tratan estos nuevos documentos, todos ellos del año 1592, incrementándose de manera más que notable el número de pruebas documentales sobre Miguel de Cervantes que se conservan en relación con el ejercicio de su cargo de comisario real de abastos en el antiguo Reino de Jaén.

Aún disponemos de escasos datos que permitan conocer con detalle cómo se desarrolló entre los años 1591 y 1592 la comisión encomendada a Miguel de Cervantes para recoger provisiones en el antiguo Reino de Jaén, y todavía lo son menos los relativos a su presencia en la villa de Porcuna. Algo sabíamos sobre esta comisión gracias a la documentación publicada en 1979 por el profesor Luis Coronas Tejada ${ }^{39}$.

El proveedor general Pedro de Isunza había encargado a los expresados comisarios la misión de comprar o requisar, si así fuera necesario, hasta 60.000 fanegas de trigo, y la cantidad de garbanzos y habas que se pudiesen hallar en una extensa lista de ciudades, villas y lugares del obispado de Jaén, y otras de las actuales provincias de Córdoba, Málaga y Granada, para el abastecimiento de las galeras de la Armada de Felipe II. Con la harina resultante de la molienda de ese trigo se fabricaría, en la ciudad de El Puerto de Santa María y en otros lugares de Andalucía, el bizcocho necesario para la alimentación del personal que prestaba sus servicios en las galeras y galeones de la Armada Imperial.

Para su estudio, Coronas Tejada utilizaría como principales fuentes documentales los libros de actas capitulares del Ayuntamiento de Jaén y los protocolos notariales conservados en el Archivo Histórico Provincial de la capital jiennense, así como los testimonios facilitados por Juan Sánchez Caballero ${ }^{40}$ y los escuetos datos publicados con anterioridad por el ilustre biógrafo cervantino Luis Astrana Marín ${ }^{41}$, de los que también se serviría Juan Antonio

39. Coronas Tejada (1979: 29).

40. Sánchez Caballero (1961: 63-65) (1962: 148-150).

41. Astrana Marín (1948-1958: V, 7-9). 
Cabezas $^{42}$ para componer su biografía de Cervantes. Finalmente, el profesor Krzystof Sliwa los agruparía en una magna recopilación de 1.703 documentos cervantinos $^{43}$.

Hasta ahora, que sepamos, el nombre de la villa de Porcuna sólo aparecía mencionado junto al de Cervantes en un par de documentos oficiales:

$1^{\circ}$. En la citada comisión de Pedro de Isunza, dada en El Puerto de Santa María el día 1 de octubre de 1591, cuyo texto íntegro va inserto en un documento notarial extendido por Pedro Núñez de Ayala, escribano público de Jaén, el 16 de noviembre de $1591^{44}$.

$2^{\circ}$. En la recepta del proveedor Gaspar de Añastro, fechada en Sevilla el 31 de marzo de 1598, para la comprobación de las cuentas presentadas por Miguel de Cervantes, comisario que fue de Pedro de Isunza ${ }^{45}$ en las comisiones de 1591 y 1592.

Astrana Marín, al referirse a la recepta de Añastro, facilita una relación de los lugares del Reino de Jaén que proporcionaron trigo y cebada a Cervantes, citando entre ellos, además de a Porcuna, la ciudad de Jaén, Martos, Alcaudete, Arjona, Lopera, Arjonilla, Linares, Begíjar, Villanueva del Arzobispo, Las Navas y Villardompardo, limitándose a decir sobre Porcuna que «(...) Cervantes, con rapidez increíble, bajó desde las tierras cordobesas a Sevilla, y el 7 de enero de 1592 extrajo en el vecino pueblo de Olivares, del mayordomo del conde del mismo título, Jerónimo del Castillo, 321 fanegas de trigo y 6 de cebada, de que dio certificación. Vuelto a Sevilla, saltó de nuevo, como en el año precedente, al obispado de Jaén. El 13 de Enero se hallaba en Porcuna, donde recibía, de lo almacenado por la villa a cuenta de las alcabalas, 196 fanegas de trigo. Encontró aquí dificultades en los acarretos del cereal; no había arrieros, o no había con qué pagarlos, y como esperaba, además, 130 fanegas de trigo y 50 de cebada de aquel Concejo, se echó a buscarlos por los contornos $(\ldots)\rangle^{46}$.

La presencia de los comisarios Ruy Sáenz y Cervantes en los lugares mencionados en la comisión de 1 de octubre de 1591, y, en su caso, de sus ayudantes en representación de aquellos, es conocida gracias a simples anotaciones o referencias que de ellos se hacen en otros testimonios, pero sin haberse podido encontrar aún la mayor parte de los documentos notariales o acuerdos municipales que así lo corroboren.

Los testimonios cervantinos que aportamos aquí, hallados entre los fondos documentales del Archivo Histórico Provincial de Sevilla, nos acercarán un poco más a la figura de Cervantes, permitiéndonos cubrir una pequeña parte de la gran laguna documental que aún existe sobre su residencia en Andalu-

42. Cabezas Candeli (1967: 298-299).

43. Sliwa, 2005.

44. Coronas Tejada (1979: 28-31).

45. De Lambarri Yanguas (1971: 16-21). Archivo General de Simancas, Libro de Contadurías Generales, legajo 1.745. Astrana Marin (1948-1958: V, 9).

46. Astrana Marín (1948-1958: V, 7). 
cía y contribuir al conocimiento de la historia de la villa de Porcuna, donde fueron protagonistas aquellos alcaldes y regidores que personalmente trataron con Miguel de Cervantes la recogida y entrega de los cereales requeridos por el proveedor general.

Como tuvimos ocasión de puntualizar al principio, los siete documentos cervantinos relacionados con Porcuna se encuentran integrados en dos cartas de pago, otorgadas en Sevilla los días 16 de octubre y 12 de noviembre de 1592, justificativas de haberse librado y pagado al Concejo de la villa un total de 4.864 reales por el valor de las 326 fanegas de trigo y 50 fanegas de cebada que en el mes de enero de ese mismo año les pudo sacar el comisario real de abastos Miguel de Cervantes Saavedra.

\title{
(DOC. VIII al XI)
}

1592, octubre, 16 Sevilla

\begin{abstract}
Carta de pago. Otorgada por Cristóbal Ramírez de Aguilera en nombre del Concejo de la villa de Porcuna, acreditativa de haber recibido de Francisco Alonso de Maluenda, en nombre de Martín de Arriaga, pagador de las galeras de España, los 2.744 reales de plata (93.296 maravedíes) que al Concejo se le debían por el valor de 196 fanegas de trigo que en enero de 1592 les compró y sacó el comisario Miguel de Cervantes. (Archivo Histórico Provincial de Sevilla, Protocolos Notariales de Sevilla $)^{47}$.
\end{abstract}

En la primera carta de pago (doc. VIII), fechada en Sevilla el día 16 de octubre de 1592, va inserto un traslado literal de una carta fechada en El Puerto de Santa María el 11 de octubre de 1592. Es una misiva del pagador Martín de Arriaga dirigida a Francisco Alonso de Maluenda, vecino de Sevilla, comunicándole la necesidad de que se pagaran al Concejo de la villa de Porcuna los 2.744 reales que se le debían por las 196 fanegas de trigo que, al precio de 14 reales la fanega, les había sacado en enero de 1592 el comisario Miguel de Cervantes; pago que debería realizarse conforme a la libranza firmada por Pedro de Isunza el 7 de septiembre de 1592 en El Puerto de Santa (doc. X), y de la cual también consta un traslado autorizado en esta misma carta de pago.

47. El documento, inédito hasta ahora, fue dado a conocer públicamente durante mi intervención en la Mesa Redonda que bajo el título Cervantes estuvo aquí. Documentos Cervantinos en los archivos andaluces, se desarrolló el pasado día 8 de junio de 2016 en el Archivo Histórico Provincial de Sevilla en conmemoración del IV Centenario de la muerte de Miguel de Cervantes y la celebración del Día Internacional de los Archivos. El original se conserva en el Archivo Histórico Provincial de Sevilla, Sección Protocolos Notariales de Sevilla, Sig. $n^{\circ}$ 5.421, Oficio $n^{\circ} 8$, protocolo del escribano público Alonso de Cívico, año 1592, Folios 573 r.- 575 v. Presenta un regular estado de conservación, con daños ocasionados por las tintas empleadas en su redacción. 
En ella se extiende, igualmente, una copia autorizada del poder especial que el 6 de octubre de 1592 (doc. IX) había otorgado el Concejo de Porcuna ante Francisco de la Chica, escribano público y del cabildo, a favor de Cristóbal Ramírez de Aguilera, vecino de Sevilla, para que pudiera cobrar del pagador Martín de Arriaga los 2.744 reales que aún se le debían por las 196 fanegas de trigo recogidas por Cervantes.

Cuando nuestro comisario hizo acto de presencia en Porcuna, la villa contaba con 1.179 vecinos, donde aún seguían funcionando las instituciones de la Orden Militar de Calatrava, bajo cuya jurisdicción se encontraba desde el año 1240 , si bien ésta ya había pasado a la Corona en el año 1523. Desde el mes de octubre de 1591, el vecindario quedaba obligado a desembolsar a la Corona un total de 5.305.500 maravedíes en concepto de tributo para poder recobrar las jurisdicciones civil y criminal de las que anteriormente había disfrutado ${ }^{48}$. Cervantes, pues, se encontró con una población que atravesaba por un mal momento económico, a la que no tendría más remedio que sacar toda “(...) la dicha cantidad de trigo, habas e garbanzos que pudieren y hayaren [en] poder de las personas que las tengan de qualquier calidad, estado e condición que sean, sin reservar ninguna dejándoles de lo que cada uno tubiere lo que hubiere menester para su sustento, comida de su cassa e familias, no más (...)"'49, concertándose con su Ayuntamiento en acopiar parte del trigo que tenía reservado para el pago de las alcabalas.

El 6 de octubre de 1592, fecha del citado poder (doc. IX), el Concejo de la villa lo formaban Pedro de Navas Valdivia ${ }^{50}$ y Francisco Martín Gregorio, como alcaldes ordinarios, los regidores Hernando de Mazuelo, Alonso de Salas,

48. (Recuerda Burgos 1995), disponible en la dirección Web: https://app.box.com/s/zh6ewucfen90uuxwwnepwdv7k1d3nn60.

49. Comisión del proveedor Pedro de Isunza, dada en El Puerto de Santa María el 1 de octubre de 1591. Coronas Tejada (1979: 29).

50. Es interesante resaltar aquí la posible vinculación familiar de Pedro de Navas Valdivia, alcalde ordinario de Porcuna, con el que fuera alcalde del Crimen de la Real Audiencia de Sevilla, el licenciado Diego de Valdivia, natural de esta villa jiennense. Este Diego de Valdivia, delegado que fue por el proveedor general Antonio de Guevara para acopiar trigo y cebada con destino a la provisión de la Armada Invencible, encomendaría a Cervantes, gracias a la mediación de Tomás Gutiérrez, amigo personal de nuestro comisario, su primera comisión para sacar trigo en Écija en septiembre de 1587. Vid. Astrana Marín (1948-1958: IV, 134-158). En la Sección Nobleza del Archivo Histórico Nacional, Osuna, C. 239, D.11, se conserva un legajo con la correspondencia dirigida a los duques de Béjar por diversas personas residentes en Porcuna, que tratan sobre varios asuntos relacionados con la administración de los bienes y rentas que el duque tenía en ella, destacando las cartas dirigidas al duque por Pedro de Navas Valdivia entre los años 1625 y 1626, donde declara ser su fiel criado. Creo que esta circunstancia es digna de tenerse en cuenta al analizar los motivos que pudieran haber llevado a Miguel de Cervantes a tomar la decisión de dedicar la primera parte del Quijote al duque de Béjar. No sería descabellado pensar en la posibilidad de que el licenciado Diego de Valdivia, quizás emparentado con Pedro de Navas Valdivia, hubiera podido solicitar de éste o de cualquier otro familiar suyo, aprovechando su condición de administrador de las rentas y bienes del duque en Porcuna y con la intención de favorecer a su amigo Cervantes, que alguno de ellos mediara ante su señor para que aceptara ser protector y mecenas del escritor. Las imágenes digitales de este expediente están disponibles en el Portal PARES: http://pares.mcu.es/ParesBusquedas/servlets/Control_servlet?accion=3\&txt_id_desc_ud $=4796600 \&$ fromagenda $=\mathrm{N}$. 
Rodrigo Pérez Hurtado, Francisco Díaz, Benito Cobos, Bartolomé de Risquel y Alonso Gómez, actuando Francisco de la Chica como escribano público y del Cabildo. Los capitulares lo otorgaron a favor de Cristóbal Ramírez de Aguilera, residente en Sevilla pero estrechamente vinculado a Porcuna, para que pudiera cobrar de Martín de Arriaga, pagador general de las galeras de España, 2.744 reales por las 196 fanegas de trigo que les sacó Cervantes en enero de 1592.

El proveedor general Pedro de Isunza expidió una libranza el 7 de septiembre de 1592 (doc. X), cuyo texto íntegro va inserto en esta carta de pago, donde queda constancia que Cervantes había sacado las referidas 196 fanegas de trigo para conducirlas a Málaga, como así lo declaró en la certificación que firmó el mismo Cervantes el día 13 de enero de 1592 (doc. XI) ante Francisco de Vargas, escribano público de Porcuna.

\section{Transcripción}

\section{2, octubre, 16 Sevilla}

// 573 r. "Sepan quantos esta carta vieren como yo Christoval Ramírez de Aguilera, vecino de esta ciudad de Seuilla en la collación de la Magdalena, en nombre y en voz del Conçejo, Justicia y Regimiento de la villa de Porcuna, de la Orden de Calatrava del Andalucía, e por virtud del poder que del dicho Conçejo tengo que pasó ante Francisco de la Chica, escribano del dicho Cabildo, en seis días deste presente mes de octubre de la fecha desta carta que adelante irá incorporada, doy, otorgo y conozco a vos Francisco Alonso Maluenda vecino desta dicha ciudad de Seuilla en la collación de Santa María que estáis presente, y digo que por quanto Martín de Arriaga, pagador general de las galeras de España, por su carta misiva fecha en el Puerto de Santa María a once días deste dicho presente mes de octubre, os ordena paguéis al dicho Conçejo de la dicha villa de Porcuna o a quien su poder especial para ello tuviere, dos mill y setecientos y quarenta e quatro reales que por libranza del proveedor Pedro de Ysunça, fecha a siete del mes de septiembre próximo pasado deste dicho presente año, se le libraron a el dicho Conçejo de la dicha villa de que está tomada la razón por el contador Pedro de Arriola y puesta la intervención del dicho proveedor, que se le libraron por el valor de çiento y noventa y seis fanegas de trigo que en el mes de enero próximo pasado deste dicho presente año le compró y sacó a el dicho Conçejo el comissario Miguel de Çerbantes para provisión de la gente ordinaria que navega en las dichas galeras, a razón e precio de catorce reales cada fanega de que le fue dada la dicha libranza como por ella pareçe, y el 
dicho Conçejo, Justicia y Regimiento de la dicha villa de Porcuna me dio su poder para reçibir y cobrar los dichos dos mil y setecientos y quarenta y quatro reales de la dicha libranza, como pareçe por el dicho poder e carta misiva e libranza, que todo lo entrego originalmente a el presente escribano para que incorpore dello un traslado en esta carta de pago y os entregue los dichos originales, e yo Alonso de Çivico, escribano público de Seuilla, yze sacar del dicho poder y carta misiva y libranza un traslado su tenor de lo qual bien e fielmente sacado, corregido e conçertado con los dichos originales que quedaron originalmente en poder del dicho Francisco Alonso Maluenda, es este que se sigue:

// 573 v. Sepan quantos esta carta de poder e causa propia vieren como nos, el Conçejo, Justicia e Regimiento de la villa de Porcuna, de la Orden de Calatrava del Andalucía, estando juntos en nuestro Cabildo como lo habemos de uso e de costumbre, conviene a saber: Pedro de Navas Valdivia y Francisco Martín Gregorio, alcaldes ordinarios; Hernando de Maçuelo, Alonso de Salas, Rodrigo Pérez Hurtado, Francisco Díaz, Benito Cobos, Bartolomé de Risquel e Alonso Gómez, regidores oficiales deste Conçejo, como Conçejo en nombre del otorgamos y conocemos que damos y otorgamos todo nuestro poder cumplido quanto bastante de derecho se requiere e más puede e debe valer, a Christoval Ramírez de Aguilera, residente en la ciudad de Seui1la, especialmente para que por sí el dicho Concejo pueda pedir y demandar y recibir, haber y cobrar en juicio y fuera del de Martín de Arriaga pagador general de las galeras de España y sus provisiones y de quien e con derecho pueda e deba, dos mill y setecientos e quarenta e quatro reales que a este dicho Conçejo se le deben por el valor de ciento y noventa y seis fanegas de trigo que el mes de enero próximo pasado deste presente año de mil e quinientos y noventa y dos sacó Miguel de Çerbantes comissario nombrado por Pedro de Ysunça, proveedor general de las dichas galeras de lo que este Conçejo thenía almacenado y recoxido por quenta de las alcabalas que debe a Su Majestad, como parece por la libranza que el dicho proveedor Pedro de Ysunça libró sobre el dicho pagador Martín de Arriaga, su fecha della en el Puerto de Santa María en siete de septiembre deste presente año de noventa y dos, como por ella pareçe más largamente a que nos referimos, e de lo que en nuestro nombre recibiere y cobrare pueda otorgar cartas de pago e finiquito e valgan como si este dicho Conçejo las diera y otorgara presente seyendo, en la razón de la cobranza siendo necesario pueda parescer y parezca ante todas e cualesquier justicias y jueces del Rey nuestro Señor y pueda poner qualesquier demandas e hacer qualesquier pedimentos, requerimientos, protestaciones, execuciones, benciones, 
trances e remates de bienes e tomar posesiones dellos e todos los demás autos e diligencias judiciales y extrajudiciales que sean necesarios de se hazer e que este Conçejo haría y hacer podría presente siendo hasta que realmente los haya cobrado, que para ello le otorgamos poder cumplido con incidencias y dependencias y con libre e general administración e con facultad de lo sostituir en quanto a autos y no más, e lo relevamos en forma, e para su firmeza obligamos los bienes e rentas deste Conçejo en cuyo nombre lo otorgamos. En testimonio de lo qual otor // 574 r. gamos esta carta de poder ante el escribano de nuestro Ayuntamiento e testigos yusoscriptos en la villa de Porcuna, en seis días del mes de octubre de mill e quinientos e noventa e dos años, siendo testigos Alonso Sánchez de Montanchez e Fernando Gutiérrez, escribano, e Rodrigo Muñoz vecinos desta villa, e lo firmaron los otorgantes que yo el escribano doy fe que conozco. Pedro de Navas Valdivia, Francisco Martín Gregorio, Alonso de Salas, Hernando de Maçuelo, Rodrigo Pérez, Alonso Gómez, Bartolomé de Risquel, Benito Calvo, Francisco Díaz. Ante mí, Francisco de la Chica, escribano del Cabildo. E yo, Francisco de la Chica, escribano del Cabildo de la villa de Porcuna por merced del Rey Nuestro Señor, presente fui en testimonio de verdad e fiçe mi signo. Francisco de la Chica, escribano del Cabildo.

Por otras he escrito a vmd. lo que se ofreçe y esto es para deçir cómo el señor provehedor Pedro de Ysunça thiene dadas sobre my una libranza de dos mil setecientos y quarenta y quatro reales de siete de setiembre deste año, a pagar a el Conçejo, Justicia y Regimiento de la villa de Porcuna de que está tomada la razón por el Señor contador Pedro de Arriola y puesta la yntervençion del dicho señor proveedor de la paga, y puesto que (...) estamos faltos de dineros y ser justo pagarla por haber de cumplir con ella el dicho Conçejo otra tanta suma que debe a $\mathrm{Su}$ Majestad de alcabalas, suplico a vmd. me haga de mandar que se paguen los dichos dos mill y setecientos y quarenta y quatro reales que valen e montan noventa y tres mill y dosçientos y noventa y seis maravedís a el dicho Conçejo de la villa de / la villa de (sic) Porcuna o a quien en su nombre y un poder bastante para cobrar esta suma, e presentarla vmd. tomando carta de pago ante escribano dando fee de la paga o de que conoce a la persona que con poder del dicho Conçejo lo cobrare, y con los dichos requisitos lo mandará vmd. poner a mi quenta e guardando la dicha librança y poder para entregármelo y Dios guarde a vmd. Del Puerto de Santa María onçe de octubre de mil e quinientos y noventa e dos. El dinero remitiré a vmd. tanto que se me haya avisado haber pagado esta libranza. El poder ha de declarar que es para cobrar la mesma cantidad de 
la librança. Martín de Arriaga. Y el sobrescripto deçia a Francisco Alonso Maluenda que Dios guarde en Sevilla.

// 574 v. Librança. Pedro de Ysunça, proveedor de las galeras de España por Su Majestad. Martín de Arriaga, pagador general de las dichas galeras, bastimentos y demás pertrechos dellas por el Rey nuestro Señor de qualesquier maravedís de su cargo que haya recibido para los gastos e distribución por libranças y horden mía en las provisiones y otros gastos de las dichas galeras, de y pague vmd. a el Conçejo, Justiçia y Regimiento de la villa de Porcuna o a quien su poder obiere, dos mil seteçientos y quarenta y quatro reales que valen noventa e tres mil doçientos y noventa y seis maravedís que se libran a pagar por el valor de çiento e noventa y seis fanegas de trigo que el mes de henero deste presente año les sacó por mi horden el comissario Miguel de Çerbantes de lo que el dicho Conçejo tenía almaçenado he recogido por quenta de las alcabalas que dan a $\mathrm{Su}$ Majestad, el qual trigo se conduçio a Málaga para provisión y manthenimiento de la gente que navega en ellas, de que dio el dicho comissario çertificacion firmada de su nombre y de Francisco de Bargas escribano de la dicha villa fecha en treze días del dicho mes de henero que original queda en mis libros, y en su virtud, hecho el cargo de las dichas çiento y noventa y seis fanegas de trigo en ellos al dicho Miguel de Çerbantes para le pedir quentas de su distribución, y a el dho Conçejo se le paga cada una fanega del dicho trigo a razón de catorze reales que es el preçio más bajo que el dicho Conçejo çertifica en ella a el tiempo que lo recibió, y tome vmd. carta de pago del dho Conçejo o de quien el dicho su poder hubiere del rescibo de los dichos dos mill seteçientos y quarenta y quatro reales que con (roto) la dicha libranza, tomando la raçon della el dicho Pedro de Arriola, contador de las galeras por Su Majestad, y fee mía de que con mi yntervençion se paga la dicha cantidad se le recibirán e pasarán en quenta los dichos noventa e tres mill y doçientos y noventa y seis maravedís sin otro recaudo alguno, no obstante questa no se tome la razón en los libros del Veedor General don Jorge Manrrique ni en los del contador Francisco de Arriola por estar ausentes e no haber de presente personas que sirvan sus ofiçios en / ellas. Datta en el Puerto de Santa María siete de setiembre de mill e quinientos e noventa y dos años. Va enmendado (...) vala. Pedro de Ysunça. Tomo la raçon. Pedro de Arriola.

Páganse con mi ynterbençion los noventa e tres mill doçientos y noventa y seis maravedís conthenidos en la librança esta otra parte. Pedro de Ysunça. 
Agora vos el dicho Francisco Alonso Maluenda, en virtud de los dichos recaudos y en cumplimiento de la dicha carta missiva que de suso va // 575 r. yncorporada, me queréis hazer la paga de la dicha suma suso referida con que yo os otorgue carta de pago de ellos, por tanto poniéndolo en efecto para que de la vía e forma que mejor haya lugar de derecho, otorgo e conozco que recibo de bos el dicho Francisco Alonso Maluenda los dichos dos mill y seteçientos y quarenta e quatro reales yuso declarados que a el dicho Conçejo, Justiçia e Regimiento de la dicha villa de Porcuna, como dicho es, se libraron por el proveedor Pedro de Ysunça por el balor de las dichas çiento e noventa y seis fanegas de trigo que en el dicho mes de henero deste dicho presente año de noventa e dos se tomaron y compraron a el dicho Conçejo por el dicho comissario Miguel de Çerbantes de la provisión de la dicha gente ordinaria de las galeras a precio de catorçe reales cada fanega como se declara en la dicha librança y recaudos que son yncorporados, los quales dhos dos mill y seteçientos e quarenta e quatro reales suso declarados me pagáis realmente y con efecto en reales de plata de contado y en presencia del escribano público e testigos yusoscriptos y son en mi poder, de que estoy contento, pagado y entregado a mi voluntad. E para la firmeça dello obligo los bienes e rentas del dho Conçejo en cuyo nombre lo otorgo, avidos e por aver. E yo Alonso de Çívico, escribano público de Sevilla, doy fee que en mi presencia e de los testigos desta carta, el dicho Francisco Alonso Maluenda dio y entregó al dicho Christoval Ramírez de Aguilera los dichos dos mill y seteçientos e quarenta e quatro reales suso declarados en la dicha moneda de reales, y el dicho Christoval Ramírez de Aguilera los recibió e quedaron en su poder, de que se otorgó por pagado a su boluntad. En firmeça de lo qual yo, el dicho Christoval Ramírez de Aguilera, otorgué la presente ques fecha la carta en Sevilla a diez y seis días del mes de octubre de mill y quinientos // 575 v. y noventa y dos años. Y el dicho otorgante, que yo el presente escribano público doy fee que conozco, lo firmó de su nombre, siendo testigos Christoval Flores y Hernando de Carmona, escribanos de Sevilla. Va enmendado quatro. Christoval Ramyrez de Aguilera (firma y rúbrica); Christoval Flores, escribano de Sevilla (firma y rúbrica); Hernando de Carmona, escribano de Sevilla (firma y rúbrica); Alonso de Çibico, escribano público de Sevilla (firma y rúbrica). Derechos: IX reales." 


\title{
(DOC. XII al XIV)
}

1592, noviembre, 12 Sevilla

\begin{abstract}
Carta de pago. Otorgada en Sevilla por Cristóbal Ramírez de Aguilera, en nombre y representación del Concejo de Porcuna, justificativa de haber recibido de Martín de Arriaga, pagador de las galeras de España, 2.120 reales por el valor de 130 fanegas de trigo y 50 fanegas de cebada que en enero de 1592 les había sacado el comisario Miguel de Cervantes. (Archivo Histórico Provincial de Sevilla, Protocolos Notariales de Sevilla ${ }^{51}$.
\end{abstract}

En la segunda carta de pago (doc. XII), expedida en Sevilla el 12 de noviembre de 1592, prácticamente un mes después de otorgarse la anterior, queda constancia de la existencia de otros dos documentos: un poder otorgado el 18 de mayo de 1592 (doc. XIII) ante Francisco de la Chica, escribano público y del cabildo de Porcuna, a favor de Cristóbal Ramírez de Aguilera, vecino de Sevilla, para que en nombre de su Concejo pudiera cobrar de los pagadores de las galeras de España los 4.864 reales que, en total, se le debían por todo el cereal que el comisario Cervantes había obtenido en enero de 1592, y una nueva libranza del proveedor general Pedro de Isunza, fechada en El Puerto de Santa María el 7 de septiembre de 1592 (doc. XIV), ordenando el pago de 2.120 reales de plata por el valor de otras 130 fanegas de trigo y 50 fanegas de cebada que en enero de ese mismo año el Concejo entregó a Miguel de Cervantes, las cuales sacó de las que estaban reservadas para el pago de las alcabalas. Estas fanegas de trigo y cebada venían a sumarse a las 196 fanegas de trigo recogidas por nuestro comisario el día 13 de enero.

Aunque el poder de 18 de mayo de 1592 autorizaba a cobrar de una sola vez el importe de todo el cereal sacado por Cervantes (326 fanegas de trigo y 50 de cebada), Pedro de Isunza, para hacer efectivo el pago de las primeras 196 fanegas de trigo, consideró necesario que el Concejo expidiera y presentara un nuevo poder en el cual única y expresamente se consignaran los 2.744 reales que fueron librados el 7 de septiembre para ello. No obstante, el mismo poder notarial de 18 de mayo serviría para recibir los 2.120 reales que restaban, librados también por Isunza en otro documento de 7 de septiembre, quedando la deuda finiquitada con esta segunda carta de pago.

51. Como el anterior, este documento ha permanecido inédito hasta ahora. Fue dado a conocer durante mi intervención en la Mesa Redonda que bajo el título Cervantes estuvo aquí. Documentos Cervantinos en los archivos andaluces, se desarrolló en el Archivo Histórico Provincial de Sevilla el pasado día 8 de junio de 2016. El original se conserva en el Archivo Histórico Provincial de Sevilla, Sección Protocolos Notariales de Sevilla, Sig, $n^{\circ}$ 5.421, Oficio $n^{\circ}$ 8, protocolo del escribano público Alonso de Cívico, año 1592, Folios 848 r.- 848 v. Aunque aparentemente el documento está bien conservado, el soporte se encuentra algo frágil. 


\section{Transcripción}

1592, noviembre, 12 Sevilla

// 848 r. "Sepan quantos esta carta vieren como yo Christoval Ramírez de Aguilera, vecino desta ciudad de Sevilla, en la collacion de la Magdalena, en nombre y en boz del Conçejo, Justiçia e Regimiento de la villa de Porcuna y por virtud del poder que del dicho Conçejo tengo que pasó ante Francisco de la Chica, escribano del dicho Conçejo, en diez y ocho días del mes de mayo próximo pasado deste presente año de mil y quinientos e nobenta e dos a que me refiero, otorgo e conozco que he reçibido e reçibi de Martín de Arriaga, pagador general de las galeras de España por Su Majestad, dos mill y ciento y veinte reales de plata de a treinta e quatro maravedíes cada uno, los quales paga al dicho Conçejo y a mí en su nombre en birtud de una librança de Pedro de Ysunça, probeedor de las dichas galeras, por el balor de çiento $\mathrm{y}$ treinta fanegas de trigo y çinquenta fanegas de çebada que por el mes de henero próximo pasado deste dicho presente año el comissario Miguel de Çerbantes sacó y compró al dicho Conçejo a los preçios y para el efecto que se contiene en la dicha libranza questá firmada del dicho probeedor y tomada la razon por Pedro de Arriola, la fecha en el Puerto de Santa María a siete días del mes de septiembre deste dicho presente año de mil y quinientos y nobenta y dos, la qual le tengo entregada originalmente con el dicho poder porque, aunque el dicho poder del dicho Conçejo es para cobrar quatro mill y ochoçíentos y sesenta y quatro reales, se me han pagado por otra librança antes de agora dos mill y seteçientos y quarenta y quatro reales que lo montó el más trigo que se tomó al dicho Conçejo, los quales reçibí del dicho pagador por mano de Francisco Alonso Maluenda, vecino desta ciudad, de que le di carta de pago ante el presente escribano público, los quales dichos dos mil y çiento y beinte reales que como dicho es, agora me ha pagado en birtud de la dicha librança el dicho Martín de Arriaga, los he reçibido del en reales de contado y son en mi // $848 \mathrm{v}$. poder de que estoy contento e pagado y entregado a mi boluntad, sobre que renunçio la exencion y leyes de la ynumerata pecunya y prueba de la paga e reçibo como en ella se contiene. En firmeza de lo qual otorgué la presente que es fecha la carta en Sevilla en doze dias del mes de noviembre de mill y quinientos y nobenta y dos años. Y el dicho otorgante, que yo el escribano público yusoscripto doy fee que conozco, lo firmó de su nombre. Testigos que fueron presentes Diego de la Rocha y Gerónimo de Aguilar, escribanos de Sevilla. Christoval de Aguilera (firma y rúbrica); Gerónimo de Aguilar, escribano 
de Sevilla (firma y rúbrica); Diego de Rocha, escribano de Sevilla (firma y rúbrica); Alonso de Çibico, escribano público de Sevilla (firma y rúbrica). Derechos: IX reales.

\section{BIBLIOGRAFIA CITADA}

Alcaide Aguilar, José Fernando (2009). «Cervantes en Marchena. Su estancia en el otoño de 1588», en Actas de las XIII Jornadas sobre Historia de Marchena. Marchena: Ayuntamiento de Marchena, pp. 105-119.

Alcalá Sánchez, Manuel (1990). "Cervantes en tierras giennenses», en Actas de las IV Jornadas de Estudios Histórico-Artísticos sobre las Cuatro Villas. Iznatoraf (Jaén), pp. 43-46.

Astrana Marín, Luis (1948-1958). Vida ejemplar y heroica de Miguel de Cervantes Saavedra, con mil documentos hasta ahora inéditos y numerosas ilustraciones y grabados de época. Madrid: Ediciones Reus, 7 tomos, disponibles para su consulta en la dirección web: http://www.publiconsulting.com/pages/astrana/index.htm.

Cabello Núñez, José (2014). «Miguel de Cervantes en La Puebla de Cazalla: un nuevo e inédito documento cervantino lo acredita, en Revista Archivo Hispalense. XVII/294296, pp. 57-71.

Cabello Núñez, José (2015). «Miguel de Cervantes, un comisario real de abastos en La Puebla de Cazalla: documentos inéditos sobre el abastecimiento de la Armada de Felipe II y la Flota de la Carrera de Indias», en Trigo y aceite para la Armada. El comisario Miguel de Cervantes en el Reino de Sevilla 1587-1593. Sevilla; Diputación Provincial, pp. 75-147.

Cabello Núñez, José (2016). «Miguel de Cervantes, comisario del Rey en Andalucía: nuevas aportaciones documentales para su biografía», en Actas de las XXIII Jornadas de Perfeccionamiento "Andalucía y América en el Barroco. Entre lo sagrado y lo profano», celebradas los días 5 al 7 de noviembre de 2015 en Écija y Fuentes de Andalucía (Sevilla) (en prensa).

Cabezas Candeli, Juan Antonio (1967). Cervantes, del mito al hombre. Madrid: Biblioteca Nueva.

Canavaggio, Jean (2005). Cervantes. Madrid: Espasa Calpe S.A., $3^{\text {a }}$ edición.

Canavaggio, Jean (2015). Cervantes, Madrid: Espasa Libros SLU, $1^{\text {a }}$ edición.

Coronas Tejada, Luis (1979). «Cervantes en Jaén, según documentos hasta ahora inéditos», en Boletín del Instituto de Estudios Giennenses. XCIX/6, pp. 9-54.

Cotarelo y Mori, Emilio (1905). Efemérides cervantinas, ó sea resumen cronológico de la vida de Miguel de Cervantes Saavedra. Madrid: Tipografía de la Revista de Archivos, Bibliotecas y Museos.

De Lambarri Yanguas, Fernando (1971). «Miguel de Cervantes Saavedra. Príncipe de los Ingenios, Comisario de Subsistencias del Cuerpo Administrativo», Ejército. Revista de las Armas y Servicios. XXXII/383, pp. 16-21.

Fernández Álvarez, Manuel (2005). Cervantes visto por un historiador, Madrid: Espasa Calpe S.A.

González Aurioles, Norberto (1912). Cervantes y el Monasterio de Santa Paula de Sevilla. Madrid: Imprenta de la viuda de A. Álvarez.

Larroque Allende, Luis (1999). «El derecho y los jueces en la España de Cervantes», Anales Cervantinos. XXXV, pp. 253-262.

León Mainez, Ramón (1901). Primera edición del Quijote en Jerez. Cervantes y su época. Jerez de la Frontera, Taller Tipográfico de la Litografía Jerezana, Tomo II. 
Lucía Megías, José Manuel (2016). La juventud de Cervantes, una vida en construcción. Madrid: Editorial Edaf.

Maganto Pavón, Emilio (2013). La familia Villafranca y Miguel de Cervantes. Nuevos documentos cervantinos localizados en el Archivo General de Indias. Alcalá de Henares: Universidad de Alcalá.

Martín Bartolomé, Alfredo (2014). «Historia de Navares de las Cuevas», en la página Web de la Asociación de Hijos y Amigos de Navares de las Cuevas, disponible en la dirección Web: http://www.freewebs.com/ahanc/historia.htm.

Martín Ojeda, Marina (2015). «Nuevos documentos sobre la estancia de Miguel de Cervantes en Écija», en Trigo y aceite para la Armada. El comisario Miguel de Cervantes en el Reino de Sevilla 1587-1593. Sevilla: Diputación Provincial, pp. 149-187.

Mayo Rodríguez, Julio (2015). «Cervantes en Utrera», Via Marciala, pp. 1-7, disponible en la dirección Web: http://www.moderna.ih.csic.es/fmi/xsl/fehm/anexos/ArtíiuloCervantesVíaMarciala-feb2015.pdf

Pérez Fernández, Antonio (2013). «Miguel de Cervantes Saavedra y la Comarca de las Villas (Jaén, Andalucía)», Argentaria, Revista Histórica, Cultural y Costumbrista de las Cuatro Villas. 3, pp. 68-85, disponible en la dirección Web: https://drive.google. com/file/d/0B_44jst5tZIcQmFId1ExLXphMmM/edit.

Recuerda Burgos, Antonio (1995). «Porcuna, Calatrava y Cervantes», en XXI Congreso de la Real Asociación de Cronistas Oficiales, celebrado en Ciudad Real los días 11 al 14 de octubre de 1995, disponible en la dirección Web: https://app.box.com/s/zh6ewucfcn90uuxwwnepwdv7k1d3nn60.

Sánchez Caballero, Juan (1961). «¿Estuvo Cervantes en Linares? Apuntes biográficos y documentales en relación con la pretendida estancia del Príncipe de los Ingenios en nuestra ciudad», Revista Oretania. 8-9, pp. 63-65; 10, pp. 148-150.

Sliwa, Krzystof (1997). «Perspectivas en los documentos cervantinos», Cervantes: Bulletin of the Cervantes Society of América. 17/1, pp. 175-180, disponible en la dirección Web: http://cvc.cervantes.es/literatura/cervantistas/coloquios/cl_VII/cl_VII_13.pdf.

Sliwa, Krzystof (2005). Documentos de Miguel de Cervantes Saavedra y de sus familiares en conmemoración del IV centenario de El ingenioso hidalgo don Quijote de la Mancha. Texas: A\&M University, disponible en la dirección web http://cervantes.tamu.edu/V2/ biografia/Sliwa_Documentos_Cervantinos_2005.pdf.

Zaragoza, Cristóbal (1991). Cervantes. Vida y semblanza. Madrid: Mondadori España S.A.

Recibido: 16 de julio de 2016

Aceptado: 30 de agosto de 2016 